\title{
An RVE Procedure for Micromechanical Prediction of Mechanical Behavior of Dual-Phase Steel
}

\author{
Hyuk Jong Bong ${ }^{\mathrm{a}}$, Hojun Lim ${ }^{\mathrm{b}}$, Myoung-Gyu Lee ${ }^{\mathrm{c}}$, David T. Fullwood ${ }^{\mathrm{d}}$, Eric R. Homer ${ }^{\mathrm{d}}$ and \\ Robert. H. Wagoner ${ }^{a^{*}}$ \\ ${ }^{a}$ Department of Materials Science and Engineering, 2041 College road Ohio State University, \\ Columbus, $\mathrm{OH} 43210$, United States \\ ${ }^{\mathrm{b}}$ Department of Computational Materials and Data Science, Sandia National Laboratories, \\ Albuquerque, NM 87185, United States \\ ${ }^{\mathrm{c}}$ Department of Materials Science and Engineering, Korea University, Seoul, 02841, South \\ Korea \\ ${ }^{\mathrm{d}}$ Department of Mechanical Engineering, 435 CTB Brigham Young University, Provo, UT \\ 84602, United States
}

\begin{abstract}
A "bottom-up" representative volume element (RVE) for a dual phase steel was constructed based on measured microstructural properties ("micro properties"). This differs from the common procedure of inferring hypothetical micro properties by fitting to macroscopic behavior using an assumed micro-to-macro law. The bottom-up approach allows the assessment of the law itself by comparing RVE-predicted mechanical behavior with independent macroscopic measurements, thus revealing the nature of the controlling micromechanisms. An RVE for DP980 steel was constructed using actual micro properties. Finite element (FE) simulations of elastic-plastic transitions were compared with independent loading-unloading-loading and compression-tension experiments. Constitutive models of three types were utilized: 1) a standard continuum model, 2) a standard Crystal Plasticity (CP) model, and 3) a SuperDislocation (SD) model similar to $\mathrm{CP}$ but including the elastic interactions of discrete dislocations. These comparisons led to following conclusions: 1) While a constitutive model that ignores elastic interaction of defects can be fit to macroscopic or microscopic behavior, it cannot represent both accurately, 2) Elastic interactions among dislocations are the predominant source of nonlinearity in the nominally-elastic region (i.e. at stresses below the standard yield stress), and 3) Continuum stress inhomogeneity arising from the hard martensite / soft ferrite microstructure has a minor role in the observed transitional nonlinearity in the absence of discrete dislocation interactions.
\end{abstract}

Keywords: crystal plasticity; dual phase steel; representative volume element; dislocation pile-up; superdislocation

*Corresponding author: Robert H. Wagoner; Tel.: 614-292-2079, email: wagoner.2@osu.edu 


\section{INTRODUCTION}

Hill [1] introduced the idea of a representative volume element ("RVE") as a material subdomain or cell to represent the microstructure of an alloy in a periodic or average sense. This "original-RVE" ${ }^{1}$ " concept was later transformed, effectively divorcing its properties from those of real microstructures and real micro properties ${ }^{2}$. As a well-known example of this "new-RVE" approach, hypothetical void arrays were constructed [2] that employed an assumed void volume fraction, typically much larger than any observed one (e.g. [3-5]. The "void fraction" thus morphed into an arbitrary internal variable in a micro-to-macro law, i.e. a model parameter in a constitutive model to allow micro-motivated FE simulation. Development of related new-RVE models [6,7] led to the field of "damage mechanics" [810]. It represents a fundamental shift away from the original-RVE concept.

When it is successful in application, the new-RVE procedure has merit for analyzing macroscale problems. However, there is no assurance that an RVE constructed in such a reverse way has any connection to the real microstructure or micro properties. The procedure instead convolutes two aspects: 1) hypothetical micro properties and 2) assumed micro-to-macro constitutive model. Only the combined pair has validity: the two cannot be separated to obtain meaningful independent components ${ }^{3}$. Clearly the procedure cannot be used to

\footnotetext{
1 The term "RVE" is used in this work for any element representing microstructural morphology and properties, whether the properties are determined from macroscopic mechanical tests and simulation ("new-RVE") or by directly-measured morphology and properties ("original-RVE"). The two RVE's may generally look the same, but as discussed may have widely varying phase properties depending on how they are obtained. Both may be useful, but not unless their limitations are taken into account in reaching conclusions.

${ }^{2}$ The term "micro property" is used here to designate the various single-crystal properties of each microstructural phases that determine its mechanical behavior: volume fraction, morphology, grain size, dislocation density, chemical composition, and strain hardening law. "Measured (or actual, or real) micro properties" denotes properties obtained from measurements corresponding to the individual grain and/or phase; this is in the spirit of the original RVE approach. "Back-fit (or hypothetical) micro properties" denotes properties obtained by assuming a law connecting micro and macro behavior, performing a macro test, such as a tensile test, then performing a reverse analysis to obtain a set of hypothetical micro properties that are consistent with the assumed law and the measured macro behavior. As will be shown, the micro and macro properties obtained in these alternate ways differ significantly, thus calling into question the accuracy of the connection law. 3 An easily-understood example of this distinction is the ubiquitous "texture analysis" performed based on a single crystal plasticity constitutive model (e.g. the PAN model [63,64,103] taking into account a statistical distribution of slip system orientations representing all of the grain orientations in an average and smoothed sense. The micro properties are inferred from macroscopic tests, e.g. tensile tests. Such a model has value in that it can predict texture-related plastic anisotropy, which relies on this scale-free average orientation.
} 
identify or confirm the microscopic mechanism controlling the macroscopic behavior, although many published results purport by inference to do this.

\section{Scale-Free Methods.}

The mechanical strength and stability of composite materials [11] has been interpreted using the new-RVE approach. Examples have been presented for elastic properties [12-14], elasticplastic properties [15,16], and cyclic behavior at room temperature [17] and at elevated temperature [18]. A key assumption inherent in such approaches is that the scale of the governing material structure is sufficiently coarse that discrete defect interactions can be ignored without large errors.

When the assumption is valid, the methods can produce accurate predictions without complex adjustments. For example, rule-of-mixtures models adequately predicted tensile strength and elongation of a steel [29] and metallic composites [30]. Such methods rely on a relationship of the following type [31]:

$$
\sigma_{\text {composite }}=V_{f} \sigma_{f}+\left(1-V_{f}\right) \sigma_{m}
$$

where $\sigma_{\text {Composite }}, \sigma_{f}$ and $\sigma_{m}$ are the flow stress of a fiber composite, fiber, and matrix, respectively and $V_{f}$ is the volume fraction of fiber in the composite. Matlock and Speer $[32,33]$ concluded that such models reproduced DP steel behavior properly, whereas Orowan models were not considered to be of practical interest. The accuracy of this conclusion is a major question to be addressed herein.

Scale-free RVE models take into account the morphology of the microstructure, but not its scale. Recently, such models have been applied to DP steels [26,27,43-51]. In most of these, the "new-RVE" approach sets the micro properties from macroscopic data, either

However, the inferred micro-properties have little or no connection with actual micro properties such as flow strength. That this is true can easily be seen by noting that the strength of the polycrystal can vary by an order of magnitude or more by changing the grain size alone via the Hall-Petch effect $[36,37]$. This change occurs with no change of the real micro properties, but in the combined model that difference of strength is attributed to spurious variation of strength of the single crystals in the single crystal constitutive model. Therefore, the final model, no matter how useful, represents neither a microstructurally-based RVE, nor a constitutive model for the constituents, as has been shown recently [60-62]. 
directly (i.e. inferring constituent strength from composite strength) [44] or indirectly (constructing and/or using a strength-vs.-chemical composition map from macroscopic measurements) $[26,27,43,45-47]$.

In order to reproduce known macroscopic properties of DP steels, the martensite phases are typically assigned unrealistic ultimate tensile strengths (UTS). For example, Ha et al. [43] set the martensite UTS at $2500 \mathrm{MPa}$ in a DP590 steel, while $1400 \mathrm{MPa}$ is expected based on direct measurements for the reported carbon concentration [52]. Similarly, Govik[44] applied a new-RVE scheme to "predict" nonlinear elastic-plastic transitions in a DP600 steel. However, the results shows that the assigned UTS of the martensite is even higher than that in $\mathrm{Ha}$ et al., at $2600 \mathrm{MPa}$. Such strengths are not consistent with any direct measurement of martensite phases of a similar composition. In fact, Govik's result tends to contradict his conclusion about identifying the proper micro-mechanism governing the nonlinearity.

New-RVE modeling for DP steel has also been performed using CP methods [53,54], rather than the purely continuum models $[43,44]$. However, the micro properties were again reverseengineered from macroscopic results and continue to ignore microstructural scales.

\section{Well-Established Scale Effects}

Scale-free models ignore well-known scale effects, for example Orowon's mechanism, or its so-called "hard pin" variation $[34,35]$

$$
\sigma=\sigma_{y}+\alpha^{\prime} \mu b / L
$$

where $\sigma_{y}$ is the yield stress with no particle, $\alpha^{\prime}$ is a constant on the order of unity, $L$ is the spacing between particles, i.e. a measure of microstructural scale, $\mu$ is the shear modulus and $b$ is the burger's vector, another measure of the microstructure scale. Changing the particle spacing by one or two orders of magnitude, holding other scales constant, alters the alloy strength inversely by one or two orders of magnitude. The only scale-independent regime is for large L in Eq. 2.

A second such effect is the variation of alloy strength with grain size $(d)$, i.e. the Hall-Petch effect [36-39]: 


$$
\sigma=\sigma_{0}+k_{y} d^{-1 / 2}
$$

where $\sigma_{0}$ is frictional stress, and $k_{y}$ is material constants. These constants can be related to more-identifiable physical constants when the dislocation pile-up length [40,41] is associated with the grain size [42]:

$$
\sigma=\sigma_{0}+M\left(\frac{\mu b \tau_{o b s}}{\pi k}\right)^{1 / 2} d^{-1 / 2}
$$

where $M$ is the Taylor factor $(\sim 3), k=1$ for screw dislocations and $k=1-v(\sim 0.7)$ for edge dislocations, and $\tau_{o b s}$ is the critical value of the stress acting on the lead dislocation that must be exceeded in order to propel the lead dislocation through the obstacle.

\section{Incorporating Scale Effects: SD Model Review}

For finer structures, the assumption of scale independence inevitably becomes inaccurate. A common ad-hoc attempt to correct for this involves embedding a fictitious length scale in an otherwise scale-free continuum constitutive model and then adjusting this parameter to reproduce the measured macro behavior. Strain-gradient theories [19-22] are examples; the length parameter is often set in complex and inconsistent ways [23-25], typically varying with every experiment and material. New experimental methods can assist by allowing measurement of properties in small volumes, for example by micro-pillar compression [50,51], high-energy X-ray diffraction [49], and nano-indentation [48].

In the current work, a novel constitutive approach contrary to that of strain-gradient methods is utilized. A modification of a standard CP procedure [55-59] is formulated in terms of a known microstructure (with scale) having known micro properties. The elastic interactions among dislocations and their equilibration are introduced. This resulting SuperDislocation ("SD") method [60-62] introduces no arbitrary parameters or length scales, but nonetheless is naturally sensitive to the actual microstructural scales. 
The SD model is implemented in Abaqus [60,61]. The governing single crystal constitutive equation is based on dislocation density [62], which has been shown to require fewer fit parameters and to be more accurate in reproducing single crystal behavior than conventional PAN (Peirce-Asaro-Needleman) models [63-65]. The SD model predicted the Hall-Petch slopes for iron accurately: $\quad 1.3 \pm 0.3 \mathrm{MN} / \mathrm{m}^{3 / 2}$ versus a measured slope of $0.9 \pm 0.3 \mathrm{MN} / \mathrm{m}^{3 / 2}$. It also predicted the reverse-deformation Bauschinger behavior of iron correctly, with no changes in the model.

The SD model was recently applied [66] to precipitation-hardened aged Al alloys [67] with very fine precipitates $(\sim 10-20 \mathrm{~nm}$ diameter, $\sim 100-200 \mathrm{~nm}$ spacing), i.e. a microstructure far removed from a composite material or pure alloys in terms of scale. It predicted the reversedeformation Bauschinger behavior of this nano-scale alloy realistically, with no adjustments needed.

\section{The Bauschinger Effect and Nonlinear Pre-Plastic Transition}

The current work compares three constitutive models representing old and new RVE approaches. The models are applied to predict the transitional behavior immediately following a strain reversal or a strain reversal. Corresponding, independent experiments are performed: loading-unloading-loading (LUL) test [76] and compression-tension (CT) test [78-80].

The LUL (strain reversal) test probes the nominally elastic behavior during unloading that has a surprising nonlinear character [68-73] not predicted by any standard elastic-plastic theory suitable for metals. Recent work revealed that in this regime the strain is reversible but is not energy-preserving ${ }^{4}$. A continuum mechanical theory of the behavior has been presented [74] and tested in several applications [68,75]. More recently, it was discovered that the nonlinearity is consistent and reproducible [76] and follows a uniform pattern among a wide range of metallic alloys [77].

\footnotetext{
${ }^{4}$ This unusual behavior has been called "mechanically reversible, thermodynamically irreversible" $[84,85]$ or "quasi-plastic-elastic" [74].
} 
The CT (stress reversal) test is conducted over larger incremental strain ranges involving plastic deformation. Typically the transitional nature of the deformation is evidenced by lower flow stresses than expected from monotonic straining. The likely micro-mechanisms for both kinds of transitional reverse-deformation effects are attributed to dislocation pinning and bowing out [81-86] and dislocation pile-up and release mechanism $[69,82,87]$.

\section{CONSTITUTIVE MODELS: FORMULATION}

Three constitutive models were developed: 1) a standard continuum model, 2) a standard CP model based on slip system geometry [23,55-58], and 3) a novel SD model essentially similar to the CP model but accounting for the discrete dislocation-dislocation, dislocationobstacle elastic interactions [60]. The continuum and CP models are scale-independent; the SD model relies on nonadjustable, known length scales corresponding to the burgers vector and one or more corresponding to the microstructure, such as grain size, precipitate size or spacing, etc.

All of the constitutive models are applied to a geometrically-identical FE mesh representing the same RVE; only the micro properties differ as stated below.

\section{Continuum model}

The continuum treats both ferrite and martensite phases as elastically identical: they are isotropic with Young's modulus of $E=208 \mathrm{GPa}$ and Poisson's ratio of $v=0.3$. The only difference in the phases is the assignment of stress-strain curves in the plastic region, each of which was represented by a Swift hardening law:

$$
\bar{\sigma}=K\left(\bar{\varepsilon}_{0}+\bar{\varepsilon}\right)^{n}
$$

where $K$ is a strength material constant, $\overline{\varepsilon_{0}}$ is a constant that may represent a pre-strain, and $n$ is the strain hardening exponent. Because of the identical elastic properties, grains and grain boundaries play no role in the continuum simulation; only the flow strength of the phases is accounted for. 


\section{CP and SD models}

The development below is intended to provide sufficient background to understand the methods and their particular implementation in the current work in brief sense. The interested reader is directed to the detailed original SD papers [60-62].

The SD and CP models discretize a polycrystal with numerous FEs in a grain. The equilibrium boundary value problem is solved in Abaqus/Standard with the choice of constitutive models being implemented through user subroutines. In both $\mathrm{CP}$ and SD implementations, a crystal plasticity framework is employed $[55,63,64,88]$. The viscoplastic shear rates of $\alpha^{\text {th }}$ slip system $\dot{\gamma}^{(\alpha)}$ is formulated as follows [55,63]:

$$
\dot{\gamma}^{(\alpha)}=\dot{\gamma}_{0}\left(\frac{\tau^{(\alpha)}-\tau_{b}}{g^{(\alpha)}}\right)^{1 / m} \operatorname{sign}\left(\tau^{(\alpha)}\right)
$$

where $\tau^{(\alpha)}$ is the resolved shear stress on the $\alpha^{\text {th }}$ slip system, $\dot{\gamma}_{0}$ is a reference shear rate, $m$ may be thought of as a strain rate sensitivity ${ }^{5}, g^{(\alpha)}$ is the slip resistance on the slip system, and $\tau_{b}$ is a back-stress that is normally zero unless a backstress can be computed (SD model only).

Both CP and SD implementations rely on a dislocation density-based single crystal constitutive equation [62]. The initial dislocation density $\rho_{0}$ is equally distributed in each element and each slip system. The slip resistance, $g^{(\alpha)}$, has initial value of $g_{0}$ and evolves with plastic shear strain on all slip systems according to

$$
g^{(\alpha)}=g_{0}+A \mu b \sqrt{\sum_{\beta=1}^{N S} \boldsymbol{h}_{\alpha \beta} \rho^{(\beta)}}
$$

where $\mu$ is the shear modulus ( $=80 \mathrm{GPa}$ for iron), $b$ is the Burgers vector $(=0.248 \mathrm{~nm}$ for iron), $\rho^{(\alpha)}$ is the dislocation density in slip system $\alpha, \boldsymbol{h}_{\alpha \beta}=\boldsymbol{n}^{(\alpha)} \boldsymbol{\xi}^{(\beta)}$ represents interaction

\footnotetext{
5 The parameter $m$ is not strictly a physical strain-rate sensitivity. It has no connection to real time. Rather, it is a mathematical convenience to simplify the apportionment of strain onto various competing slip systems. This is a characteristic of the standard visco-plastic formulations for polycrystals in common use.
} 
cosine, where $\boldsymbol{n}^{(\alpha)}$ and $\boldsymbol{\xi}^{(\beta)}$ are the slip plane normal of slip system $\alpha$ and the dislocation line vector of slip system $\beta$, respectively. The parameter $A$ is a material constant which has been measured or calculated, and ranges from 0.3-0.6 [89-92]. Here, a value of 0.4 is assumed for both CP and SD models.

The evolution of the dislocation density on each slip system is calculated according to a widely used phenomenological dislocation density evolution equation [93]:

$$
\rho^{(\alpha)}=\frac{1}{b}\left(\frac{\sqrt{\sum_{\beta}^{N S} \rho^{(\beta)}}}{k_{a}}-k_{b} \rho^{(\alpha)}\right) \gamma^{(\alpha)}
$$

where $k_{a}$ and $k_{b}$ are material parameters related to dislocation generation and annihilation, respectively.

The foregoing completes the $\mathrm{CP}$ formulation. The remainder of this section describes the additional steps in the SD formulation to account for elastic dislocation-dislocation interactions and dislocation-obstacle interactions.

In the SD treatment, the dislocation density for each slip system in each element, as described in Eq. (8) is treated as a superdislocation at the element centroid. Then, mobile dislocation contents are calculated to accommodate the strain gradient computed from the $\mathrm{CP}$ subroutine based on Orowan's equation [94]:

$$
\dot{\rho}_{\text {pass }}^{(\alpha)}=\frac{1}{b l^{(\alpha)}} \dot{\gamma}^{(\alpha)}
$$

where $\dot{\rho}_{\text {pass }}^{(\alpha)}$ is the rate of dislocation density passing through the element, and $l^{(\alpha)}$ is the length of the element parallel to the slip plane $\alpha$. The redistributed dislocation densities (represented by a superdislocation on each slip system in each element) are used to calculate the elastic interaction force between superdislocations in each element analytically, which are equivalently represented by $\tau_{b}$ in Eq. (6) at each superdislocation location. 
The SD model enforces the dislocation obstacle character of grain boundaries based on the SWC $2^{\text {nd }}$ criterion (Shen, Wagoner, Clark [95]):

$$
\tau_{\text {obs }}=(1-N) \tau^{*}
$$

where $\tau_{o b s}$ is the obstacle strength, $\tau^{*}$ is the unknown maximum obstacle strength estimated as 5 times of macroscopic yield stress for 304 stainless steel by Shen et al. [95], and $N$ is geometrical transmissivity factor determined as follows:

$$
N=\left(L_{1} \cdot L_{i}\right) \times\left(s_{1} \cdot s_{i}\right)
$$

where $L_{1}$ and $L_{i}$ are the intersection line vectors between grain boundary and slip planes, and $s_{1}$ and $s_{i}$ are the slip direction vectors of incoming and transmitted dislocations, respectively.

The obstacle strength was incorporated for grain boundary elements using the following equations:

$$
\begin{array}{ll}
\tau_{\text {eff }}^{(\alpha)}>\tau_{\text {obs }}^{(\alpha)} & \dot{\gamma}^{(\alpha)}=\dot{\gamma}_{0}\left(\frac{\tau_{e f f}^{(\alpha)}-\tau_{o b s}^{(\alpha)}}{g^{(\alpha)}}\right)^{1 / m} \operatorname{sign}\left(\tau_{e f f}^{(\alpha)}-\tau_{o b s}^{(\alpha)}\right) \\
\tau_{e f f}^{(\alpha)} \leq \tau_{o b s}^{(\alpha)} & \dot{\gamma}^{(\alpha)}=0
\end{array}
$$

\section{CONSTITUTIVE MODELS: PARAMETER IDENTIFICATION}

The intention of the bottom-up approach is identify the micro properties of each phase, assemble them into an "original-RVE" FE model and then simulate macroscopic behavior for comparison with macroscopic experiments. In the current method, the only macroscopic information used in setting the parameters is a single point (one stress strain pair from a tensile test) in order to establish the overall strength. This is necessary because it is difficult to know precisely the minute chemical composition and its role in solute solution strengthening, lattice friction stress (Peierls stress), and so on. Most importantly, none of the data for reverse tests (LUL or CT) is used in setting any constitutive parameters. 


\section{SD Model}

The parameters needed to complete the SD consists of 3 common elastic constants, $\mathrm{C}_{11}, \mathrm{C}_{12}$, and $\mathrm{C}_{44}$, plus 5 parameters for each of the two phases ( $i$ representing ferrite or martensite): $k_{a}$, $k_{b}, \quad \rho_{0}{ }^{i}$ (Eq. (8)), $g_{0}^{i}$ (Eq. (7)) and $\tau_{\text {obs }}{ }^{i}$ (Eq. (10)) $)^{6}$.

The elastic constants for iron single crystals are well-known: $C_{11}=242, C_{12}=150$ and $\mathrm{C}_{44}=112 \mathrm{GPa}[42,96]$. The plastic strain hardening of iron single crystals in various tensile orientations has been presented [97]. The parameters $k_{a}$ and $k_{b}$ (in Eq. (8)) for both ferrite and martensite were obtained by fitting to Keh's [97] multi-slip (4 equal slip systems) data for [001] tension and then verified for double slip [011] and single slip [-348] cases. The full procedure and results appear in detail in [62]. Fig. 1, after Lee et al. [62], compares the SD-predicted stress-strain curve for the double slip [011] case using the obtained constitutive parameters by fitting to the [001] tension case of Keh's experimental results.

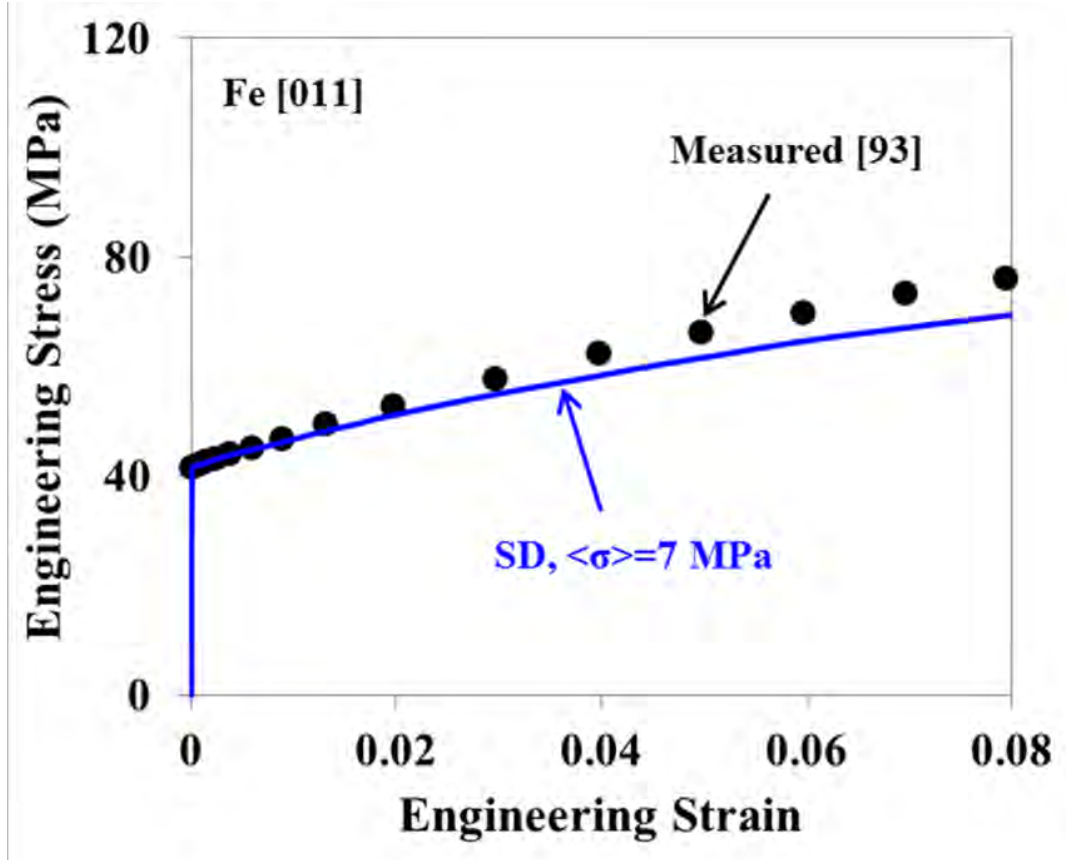

6 The local grain boundary property represented by $\tau_{o b s}$ was characterized by following early works [60], i.e. $\tau^{*}$ to be 5 times the macroscopic yield stress. 
Fig. 1 Comparison of the stress-strain curves from the SD model prediction and experimental measurement from the literature for iron single crystal with tensile axis aligned along [011]. (After Lee et al. [62])

The initial dislocation densities $\rho_{0}{ }^{i}$ for each slip system in each phase were calculated from overall dislocation density reported in the literature: $9 \times 10^{13} / \mathrm{m}^{2}$ for ferrite [98] and $1.6 \times 10^{15} / \mathrm{m}^{2}$ for martensite [99]. This total value was partitioned equally onto all slip systems and distributed equally in all elements. That is, for the 24 slip systems considered here, the initial dislocation density on each slip system in each element was $0.38 \times 10^{13} / \mathrm{m}^{2}$ for ferrite and $0.67 \times 10^{14} / \mathrm{m}^{2}$ for martensite.

Uniaxial tension of 3D array of grain assemblies having 27 grains with 13824 total elements of C3D8 (8-node solid element) type shown in Fig. 2 (a) was simulated for each phase separately using the SD model. Random crystallographic orientation was assigned to grains. Considering the measured average grain size of DP980 steels, each grain has dimensions of $1.43 \times 1.43 \times 1.43{\mu \mathrm{m}^{3}}^{3}$ for ferrite and $0.93 \times 0.93 \times 0.93{\mu \mathrm{m}^{3}}^{3}$ for martensite [100,101]. Symmetry boundary conditions are applied to the $\mathrm{x}-, \mathrm{y}-$, and $\mathrm{z}$ - planes. A prescribed displacement boundary condition is imposed to the positive $\mathrm{x}$-plane ${ }^{7}$. The bonding between the two phases is assumed to be perfect, i.e. no interface separation or sliding is allowed.

\footnotetext{
7 Simulations with alternate boundary conditions such as periodic boundary conditions were compared with symmetry conditions. The results differed insignificantly.
} 


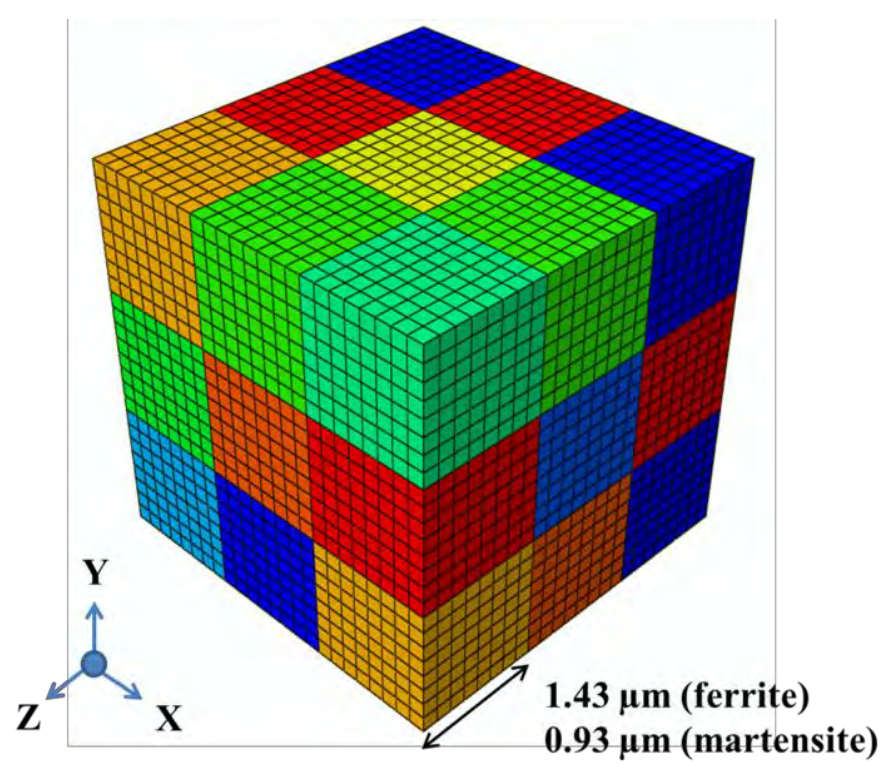

(a)

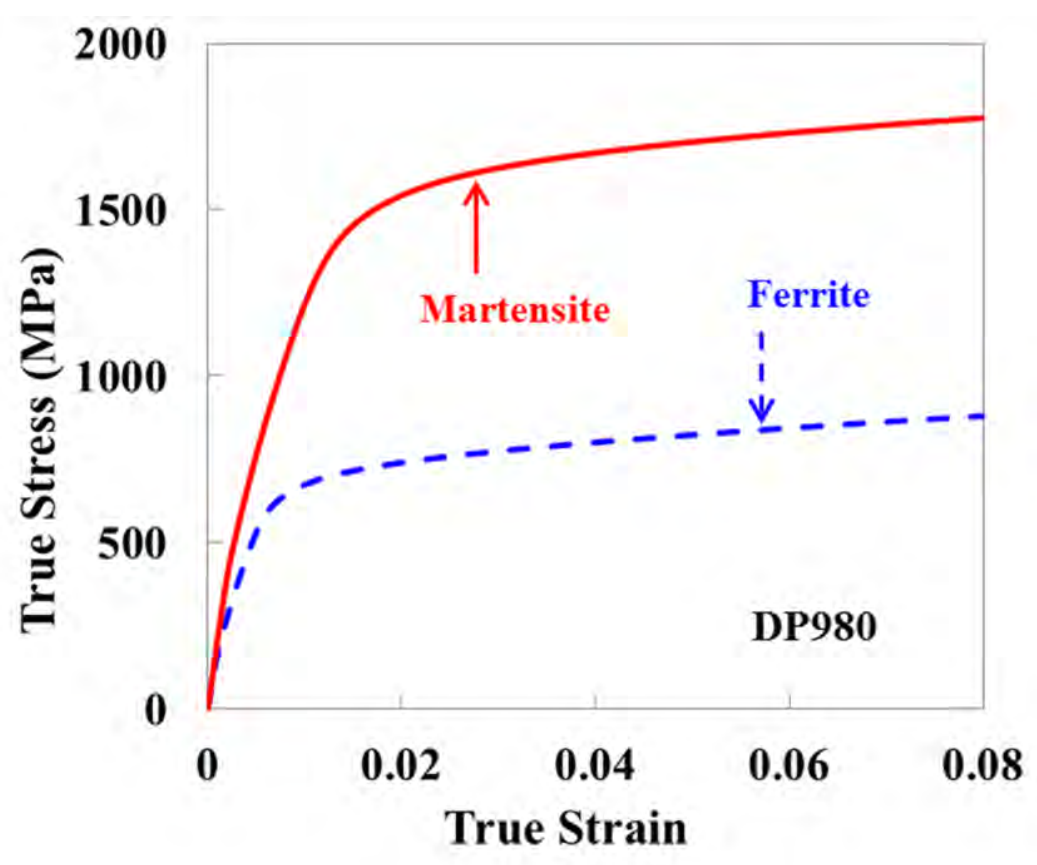

(b)

Fig. 2 (a) Configuration of 3D array of grain assembly for tension simulations (b) predicted macroscopic properties of ferrite and martensite in the DP980

The initial slip resistance $g_{0}{ }^{i}$ is the same for all slip systems (i.e. for all values of i) in one phase. Its value is set using one stress-strain pair (measured or determined from other 
single-phase data). For DP 980 in the current work, estimated tensile curves were determined from results in the literature based on the grain size for ferrite and the carbon content for martensite, as described below.

The ferrite has an average grain size of $1.43 \mu \mathrm{m}$, as reported for 11 DP980 steels [100,101]. The yield stress can therefore be estimated as $500 \mathrm{MPa}\left(\tau^{*}\right.$,ferrite $\left.=2500 \mathrm{MPa}\right)$ based on HallPetch data for 38 ultra-fine grained bcc steels [102]. The $g_{0}{ }^{\text {ferrite }}$ was set to reproduce this estimated yield stress in the ferrit with a grain size of $1.43 \mu \mathrm{m}$.

The martensite has an carbon content of $0.025 \%$, as determined a the average alloy content for 11 DP980 steels [100,101] used in conjunction with Thermo-Calc. For this carbon content, a UTS of $1650 \mathrm{MPa}$ is obtained from data presented by Krauss [52].

To identify the $\tau^{*}$,martensite , the yield stress of martensite is calculated by rule-of-mixture, Eq. (1), with known average yield stress of 11 DP980 steels [100,101] and yield stress of ferrite $(=500 \mathrm{MPa}) . \tau^{*}$,martensite is calculated as $5315 \mathrm{MPa}$ (yield stress of martensite $=1063 \mathrm{MPa}$ ). The SD simulation of this martensite is used to set the $g_{0}^{\text {Martensite }}$ such that the simulated UTS is $1650 \mathrm{MPa}$. The predicted stress-strain responses of the two phases using the determined constitutive parameters (listed later in Table 1) are shown in Fig. 2 (b).

\section{CP and continuum model}

The constitutive parameters needed to complete standard CP and continuum models use the basic polycrystal phase model shown in Fig. 2 (a). The procedure is similar to the SD determination.

The elastic constants in the CP model are the same as the SD model above. The remaining parameters, for each phase, are as follows: $k_{a}, k_{b}, \rho_{0}{ }^{i}$ (Eq. (8)), and $g_{0}{ }^{i}$ (Eq. (7)) (where i represents ferrite or martensite). The same $g_{0}{ }^{i}$ 's determined for the SD model are assumed 
in the CP model. $\rho_{0}{ }^{i}$ 's and $k_{a}$ and $k_{b}$ are fit to reproduce that phase's SD-simulated stressstrain response shown in Fig. 2 (b). In order to compare esoteric predicted mechanical responses, such as Bauschinger effect and nonlinear pre-yield behavior, it is first necessary to calibrate CP and continuum models to reproduce at least approximately a tensile test. Since the SD model does reproduce that remarkably well as will be shown later-see Figs. 4, we simply calibrate the $\mathrm{CP}$ and continuum parameters to the SD tensile test, which is virtually identical to the experimental one. Then, differences among the predictions of Bauschinger effect and nonlinear pre-yield behavior can be attributed to model differences, not to different tensile behavior. This procedure inevitably produces an error of overall strength of the CP RVE simulation for the DP980 steel as compared with the experiment and SD simulation because the interaction of dislocations with the phase boundaries is ignored. In order to calibrate the phase strengths, proportional to $\sqrt{\rho_{0}^{i}}$ 's from Eq. (7)), the magnitudes of $\sqrt{\rho_{0}^{\text {ferrite }}}$ and $\sqrt{\rho_{0}^{\text {martensite }}}$ are multiplied by a single constant such that the macroscopic strength of the DP980 steel is reproduced, while maintaining the ratio of $\sqrt{\rho_{0}^{\text {ferrite }}} / \sqrt{\rho_{0}^{\text {martensite }}}$ constant. Without such an adjustment, it is difficult to compare simulations and predictions of LUL and CT tests, which involve a certain starting stress level before the reversal ${ }^{8}$. The determined constitutive parameters are listed in Table 1. Note that, the Hall-Petch effect, absent in the CP model, is compensated for by a higher initial dislocation density of each phase.

The continuum model utilizes the Swift strain hardening law (Eq. (5)). The constants $K^{i}$, ${\overline{\varepsilon_{0}}}^{i}$, and $n^{i}$ are fit for each phase to reproduce that phase's SD-simulated stress-strain response shown in Fig. 2 (b). Again, this procedure inevitably produces an error of overall strength of the continuum RVE simulation for the DP980 steel. Similar treatment used for the CP model is adopted. Here, the ratio of $K_{\text {ferrite }} / K_{\text {martensite }}$ is kept constant and a single constant

\footnotetext{
${ }^{8}$ From purely LUL experimental data of 26 diverse alloys, the unloading stress was found as the only controlling parameter of the nonlinear behavior.
} 
is multiplied to $K_{\text {ferrite }}$ and $K_{\text {martensite. }}$ The determined constitutive parameters are listed in Table 1.

It should be noted that in the SD model only a single constant representing overall strength is fit; all other constants are derived from single crystal properties available in the literature.

Table 1 Constitutive parameters for the three constitutive models

\begin{tabular}{|c|c|c|c|c|c|c|c|}
\hline & \multicolumn{2}{|c|}{$\mathrm{CP}$} & \multicolumn{2}{|c|}{ SD } & & \multicolumn{2}{|c|}{ Continuum } \\
\hline & Ferrite & Martensite & Ferrite & Martensite & & Ferrite & Martensite \\
\hline $\begin{array}{c}\rho_{0} \\
\left(/ \mathrm{m}^{2}\right)\end{array}$ & $3.97 \times 10^{15}$ & $1.52 \times 10^{16}$ & $8.93 \times 10^{13}$ & $1.63 \times 10^{15}$ & $\begin{array}{c}K \\
(\mathrm{MPa})\end{array}$ & 1340 & 2285 \\
\hline$k_{a}$ & & 1 & & 9 & $\overline{\varepsilon_{0}}$ & 0.030 & 0.0001 \\
\hline$k_{b}$ & & $0 \mathrm{~b}$ & & $b$ & $n$ & 0.207 & 0.076 \\
\hline $\begin{array}{l}\tau^{*} \\
(\mathrm{MPa})\end{array}$ & & - & 2500 & 5315 & & & \\
\hline $\begin{array}{l}g_{0} \\
(\mathrm{MPa})\end{array}$ & 37 & 113 & 37 & 113 & & & \\
\hline
\end{tabular}

b Burgers vector $(=0.248 \mathrm{~nm})$

\section{RVE for DP980}

RVE's for DP980 steel are shown in Fig. 3. A total of 9261 elements of C3D8 type are modeled. The elements are divided into ferrite and martensite phases as shown, with measured martensite volume fraction of $\sim 32 \%$ of the 11 DP980 steels [100,101]. Martensite islands of various shapes (elongated and spherical) and sizes are randomly embedded in the ferrite sea. The element size $\left(3.02 \times 3.02 \times 3.02 \mu^{3}\right)$ and the number of grains for each phase ( 6 for ferrite and 11 for martensite) are modeled based on the measured average grain size of each phase and martensite volume fraction of the 11 DP980 steels [100,101]. Random crystallographic orientation is assigned to grains. The same symmetry boundary condition used for the uniaxial tension in Fig. 2 (a) is applied. For $\tau^{*}$ between the two phases, the 
value from the phase being entered by the transmitted dislocations was adopted: $5315 \mathrm{MPa}$ for martensite and $2500 \mathrm{MPa}$ for ferrite.
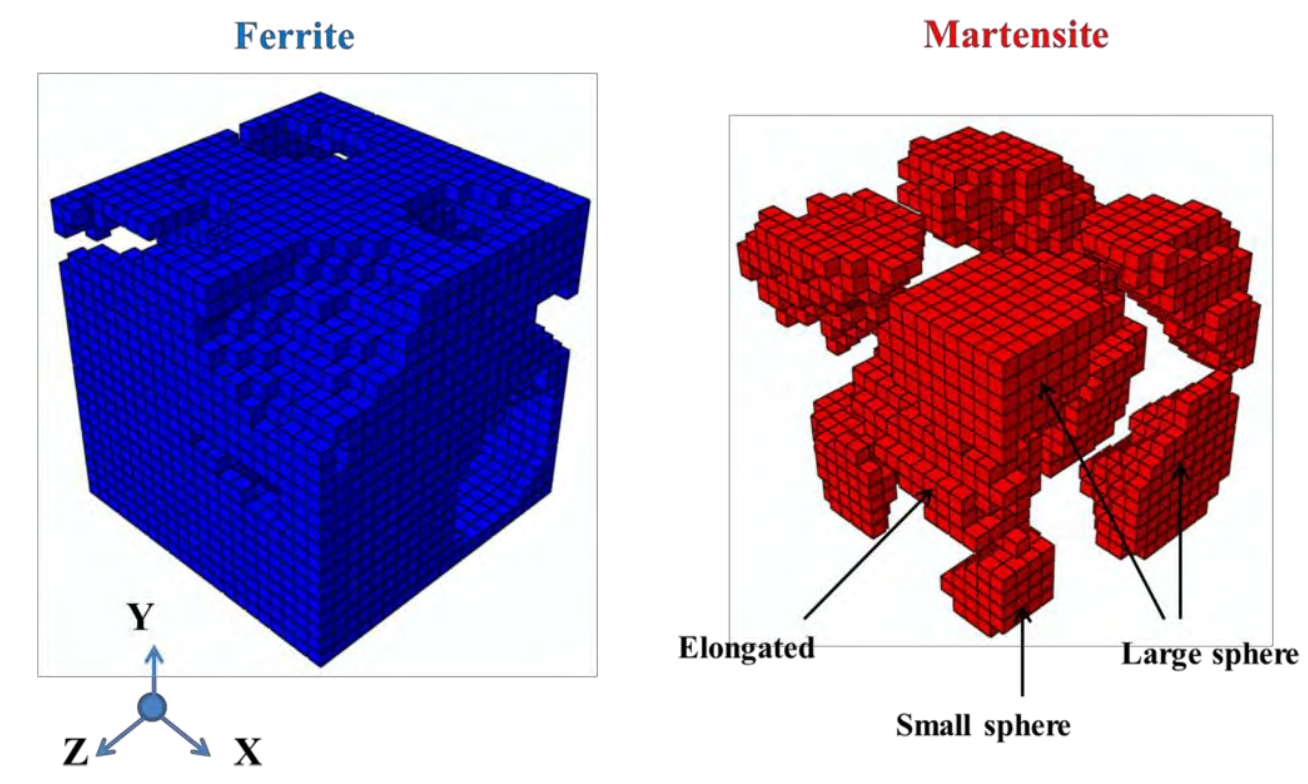

Fig. 3 RVE for the DP980 steel

The SD predicted tensile stress-strain behavior is shown in Fig. 4 (a) and compared with independent experimental results for 3 tested DP980 steels provided by supplier 1,2, or $3^{9}$. The RVE predicts the basic stress-strain behavior reasonably well in approximately the middle of the range. Note that none of the tensile data, from any DP980 test, was used in constructing the SD model. Thus, Fig. 4 (a) represents a pure prediction of macro stress-strain from micro properties only. The prediction is closer to the observed behavior than the experimental scatter among the single grade of 3 DP980 steels produced by a range of steel makers. Only for CP and continuum models, it is necessary to use a stress point to calibrate phase strength. The stress-strain curve of the DP980-1 is closest to the SD prediction and is therefore selected as a representative for further comparisons of other tests. To illuminate the importance of the calibration in the $\mathrm{CP}$ and continuum, the predicted stress-strain curves without such a calibration, i.e., original-RVE (bottom-up) approach, are also shown in Fig. 4

\footnotetext{
${ }^{9}$ The 3 DP steels refer to materials tested at OSU. They are different ones from the 11 DP 980 steels reported in $[100,101]$.
} 
(b). The results reveal that both models inevitably underestimate overall strength due to the neglect of the dislocation interaction effect between two phases. Therefore, new-RVE (topdown) approach shown in Fig. 4 (a) with the phase strength adjustment is applied to CP and continuum models to ensure the similar strength at the commencement of the load reversal. 


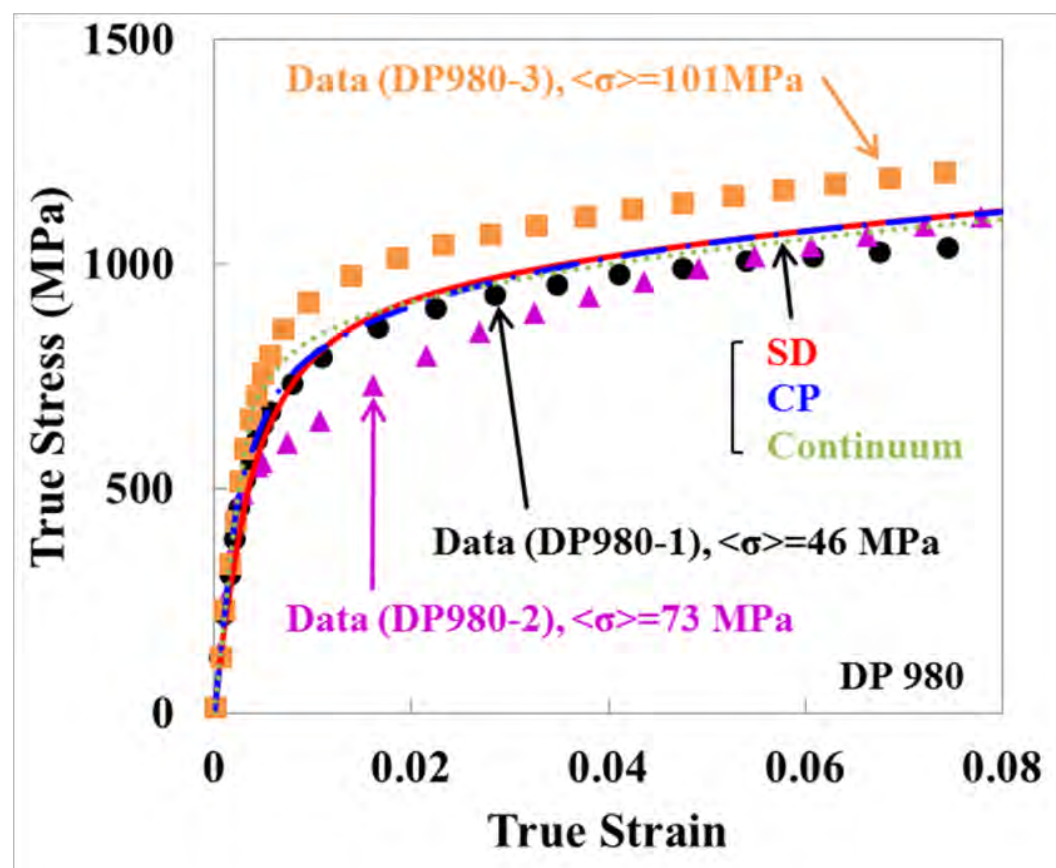

(a)

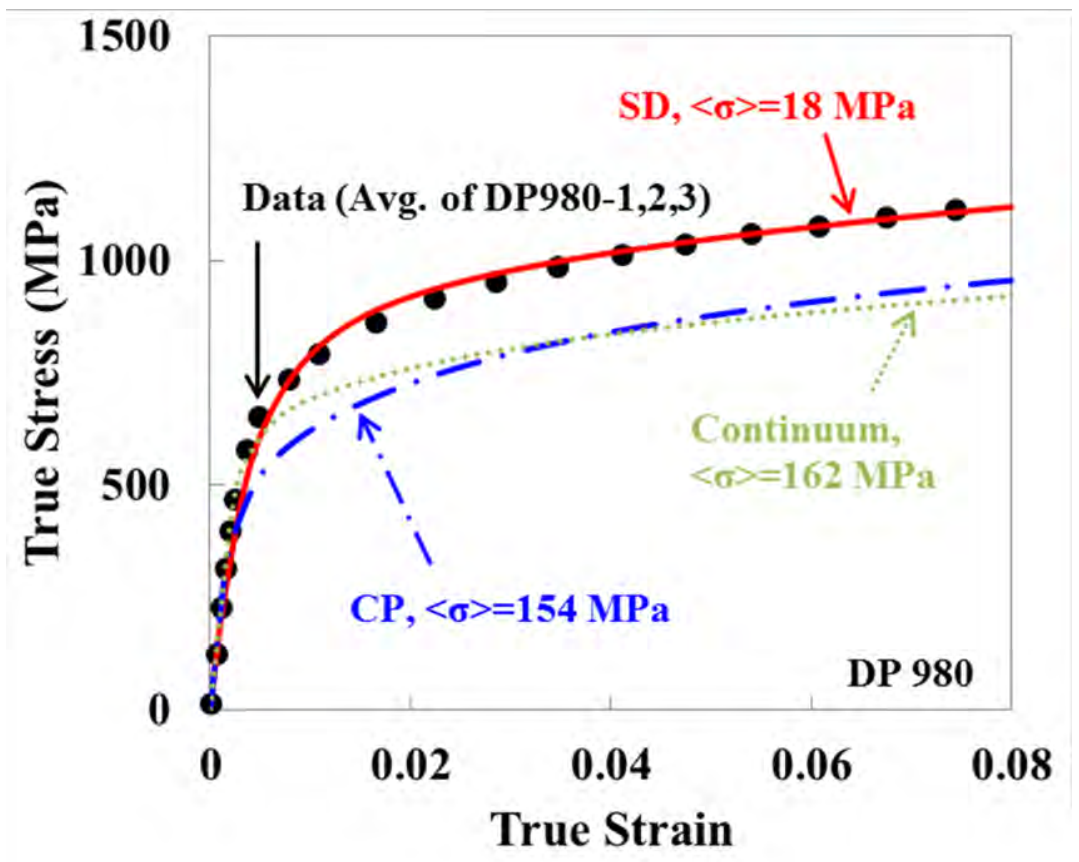

(b)

Fig. 4 Stress-strain behavior (a) predicted by the SD model and measured data for 3 DP980 steels provided by supplier 1,2 , or 3 . Contrary to SD prediction, the $\mathrm{CP}$ and continuum models are adjusted to reproduce the flow stress at $4 \%$ of the SD prediction, and (b) predicted 
by the SD model and average of measured data for 3 DP980 steels. The CP and continuum models are not adjusted.

\section{Results}

The foregoing completes the combined RVE/constitutive models for the 3 cases. We turn now to new independent experiments and predictions using the 3 models.

\section{Loading-Unloading-Loading (LUL) tests}

Results from loading-unloading-loading (LUL) tests from literature [76,77] were used. Details of the testing appear in those references. They are summarized briefly here. Following ASTM E-8 samples in the rolling direction (RD) were tested at room temperature at a displacement rate of $0.08 \mathrm{~mm} / \mathrm{s}$, corresponding to a nominal strain rate of $0.001 / \mathrm{s}$. Strain was measured using an Epsilon Class A extensometer (3452-0200-030-ST) of 2" gage.

An experimental LUL stress-strain curve for a $4 \%$ prestrain test is shown in Fig. 5 (a). Nonlinear transition behavior is clearly observed, resulting in a hysteresis loop. The data was transformed to a $(\Delta \varepsilon, \Delta \sigma)$ basis defined relative to the first data point following reversal: $\left(\varepsilon_{r}, \sigma_{r}\right)$. More explicitly, $\Delta \varepsilon\left(=\left|\varepsilon_{\text {measrued }}-\varepsilon_{r}\right|\right)$ and $\Delta \sigma\left(=\left|\sigma_{\text {measrued }}-\sigma_{r}\right|\right)$. The instantaneous tangential moduli $E_{T}(=d \Delta \sigma / d \Delta \varepsilon)$ were calculated by taking a least-squares lines passing through 10 adjacent strain, stress $(\Delta \varepsilon, \Delta \sigma)$ data points. The interval for the next $E_{T}$ used 10 data points that overlapped the previous interval by $6 \Delta \sigma(\Delta \varepsilon)$ data points. The $E_{T}$ vs. $\Delta \varepsilon$ form of plot reveals more sensitively the nature of the nonlinear response, as shown in Fig. 5 (b). Figs. 5 (c) and (d) are similar to Fig. 5 (b) except that the independent variable is $\Delta \sigma$ rather than $\Delta \varepsilon$. The figures look similar, the former one causes plotting range problems for the continuum and $\mathrm{CP}$ predictions. That is, (almost) no reduction of $E_{T}$ during the unloading results in very narrow range of $\Delta \varepsilon$ until the stress becomes zero at full unloading. The $E_{T}$ vs $\Delta \sigma$ plots are used for most subsequent analyses. The results in Fig. 5 show very clearly that CP and continuum simulations, when based on real phase properties and even when they reproduce a tensile test adequately, do not simulate observed unloading behavior or reverse loading behavior. The deviation is several 
times that of the SD predictions, which had no parameters fit to match the tensile behavior. Numerically the standard deviations of $E_{T}$ are 2.5-3 times greater for CP and continuum models. Since the only difference between $\mathrm{CP}$ and SD simulations is the inclusion of dislocation-dislocation elastic interactions in SD (and its neglect in CP), it is concluded that these interactions are the basis for these effects, i.e. nonlinear unloading and reloading in a nominally elastic regime. 


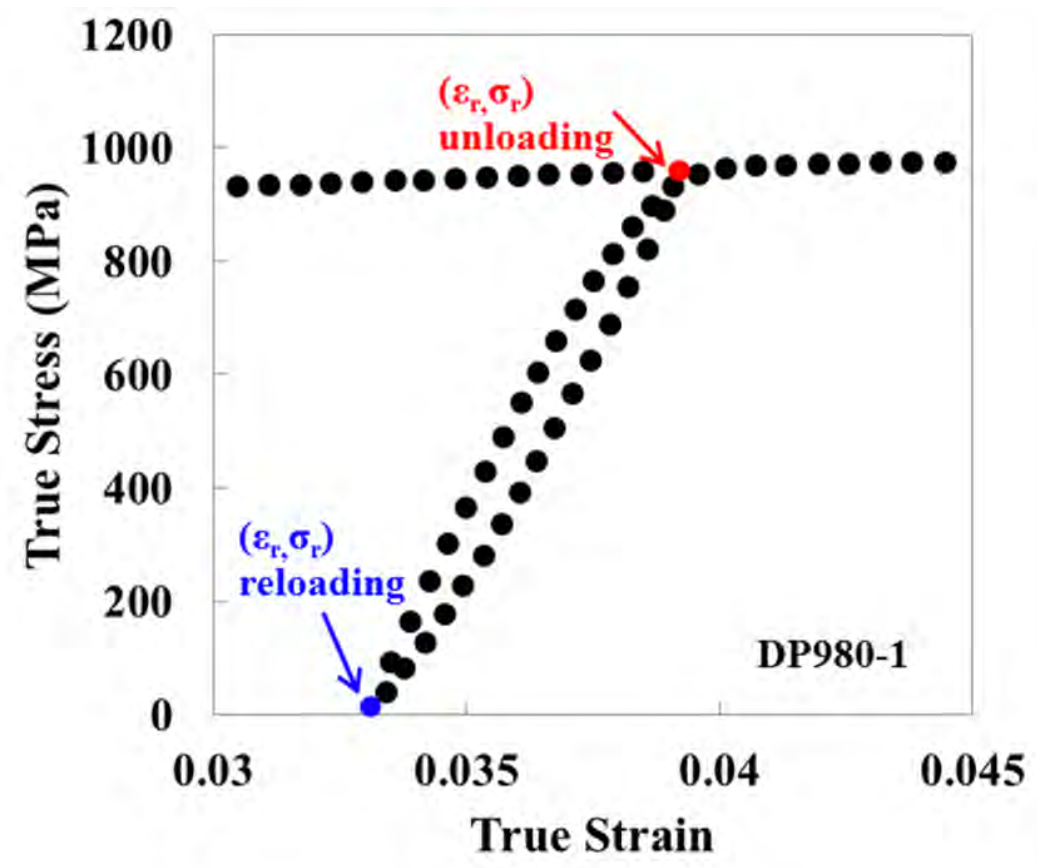

(a)

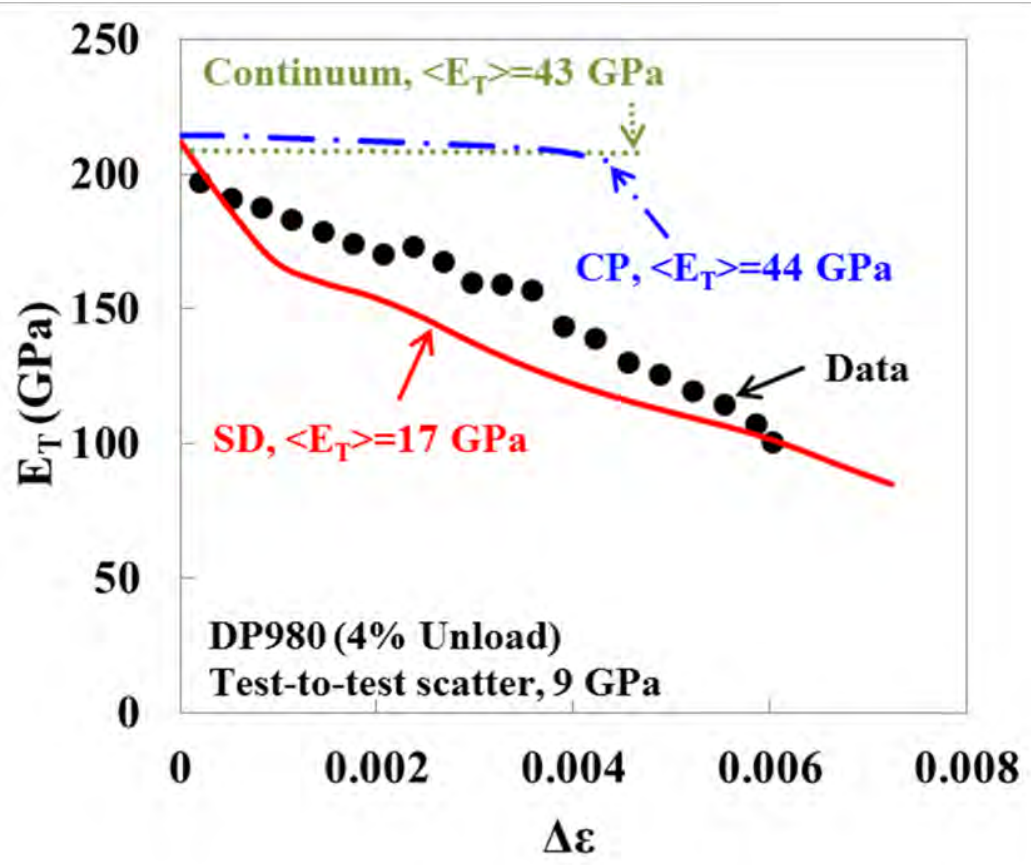

(b) 


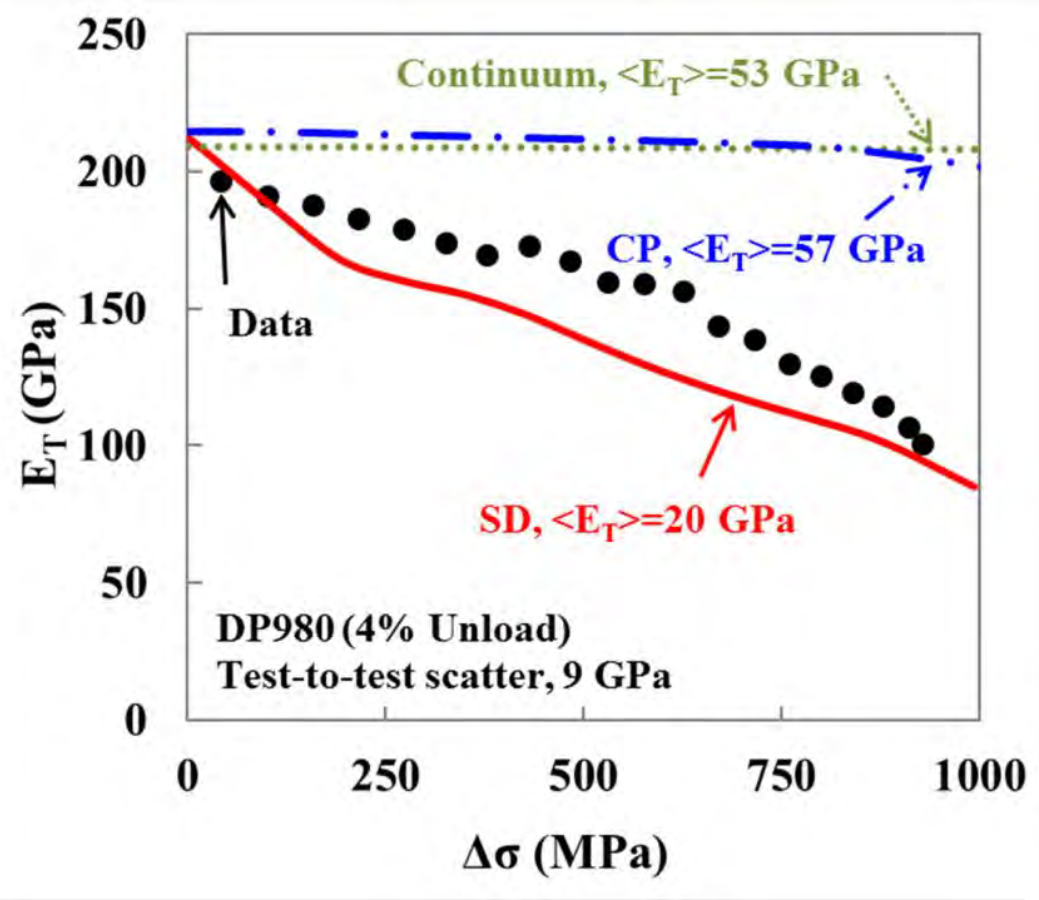

(c)

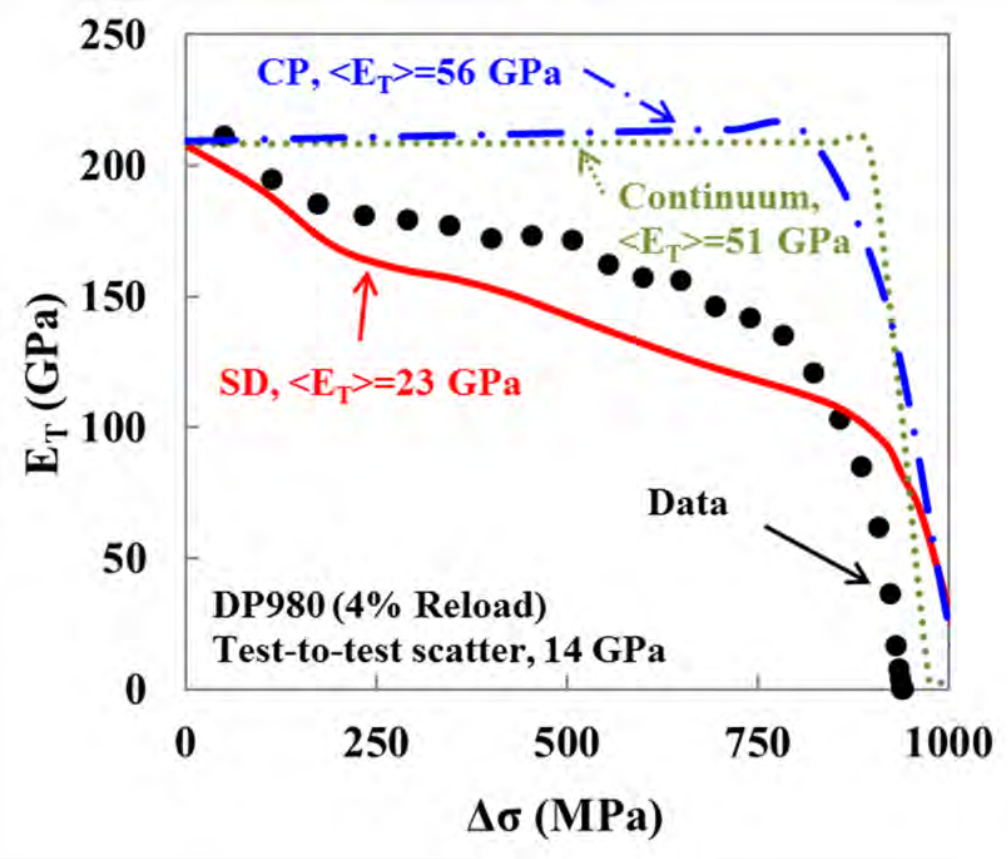

(d)

Fig. 5 A hysteresis loop for a LUL test at 4\% pre-strain (a) stress-strain, (b) tangent modulus $E_{T}$ vs. $\Delta \varepsilon$, unloading leg, (c) tangent modulus $E_{T}$ vs. $\Delta \sigma$, unloading, and (d) tangent modulus $E_{T}$ vs. $\Delta \sigma$, reloading. 


\section{Compression-tension test}

In order to observe transitional behavior following a significant increment of plastic strain, special compression-tension (CT) tests were conducted in the RD at a pre-strain of $-3.85 \%$ (its absolute value in true strain is equivalent to that of $4 \%$ prestrain in tension). The CT tests utilized an optimized sample design to suppress buckling and extend the compressive range attainable [78-80]. Tests were conducted at room temperature and s displacement rate of $0.037 \mathrm{~mm} / \mathrm{s}$, equivalent to a nominal strain rate of $\sim 0.001 / \mathrm{s}$, identical to the LUL tests. The strain was measured using a non-contact $\mathrm{EIR}^{\mathrm{TM}}$ laser extensometer, with data collected at 100 Hz. Compensation for biaxiality and friction was done using the procedure described in [79]; a friction coefficient of 0.08 was determined by minimizing the standard deviation of tensile stresses with and without side plate pressure over a strain range of 0.02 to $\varepsilon_{r}$ (strain at stress reversal).

The CT stress-strain behavior is shown in Fig. 6 (a), compared with monotonic tension data to make the transitional response clear. The evolution of $E_{T}$ following the stress sign change was calculated by averaging every 90 data points, with adjacent intervals overlapping by $60 \Delta \sigma(\Delta \varepsilon)$ data points. This procedure ensures that a strain interval similar to that in the LUL data analyses is used to determine the slope.

The experimentally measured $E_{T}$ during the unloading in the LUL test and during the unloading (i.e. reduced tension) leg of the CT test ${ }^{10}$ is compared as a function of $\Delta \sigma$ in Fig. 6 (b). The CT test result shows familiar larger scatter as a result of stick-slip friction and the reduced precision of laser extensometer. Nevertheless, there is no systematic variation in the two tests, as would be expected. In view of the improved consistency and precision of the LUL test, the final plotting modulus values up to zero stress in the CT test are replaced by the equivalent LUL experimental data and used for the further plotting.

10 The test-to-test scatter of $2 \mathrm{CT}$ tests is calculated as $36 \mathrm{GPa}$. 
The prediction of $E_{T}$ using the $3 \mathrm{RVE} /$ constitutive models for CT tests is compared with the experimental data in Fig. 6 (c). The $\mathrm{CP}$ and continuum models predict no significant reduction of $E_{T}$ until $\Delta \sigma \sim 850 \mathrm{MPa}$ and $1200 \mathrm{MPa}$, respectively, but predict abrupt reduction of $E_{T}$ afterward, as expected for a standard linear elastic-plastic yielding transition. Conversely, although the SD model slightly overestimates the $E_{T}$ reduction (or lower value of $E_{T}$ ), it captures the form of the gradual reduction of $E_{T}$ over the range observed in the experiment. The SD model represents the experimental data 5 times more accurately ( 5 times smaller standard deviation of $E_{T}$ ) than the standard methods without consideration of elastic interactions among dislocations. For the extended range, including unloading and reloading, the entire behavior is determined mechanistically by dislocationdislocation interaction effects.

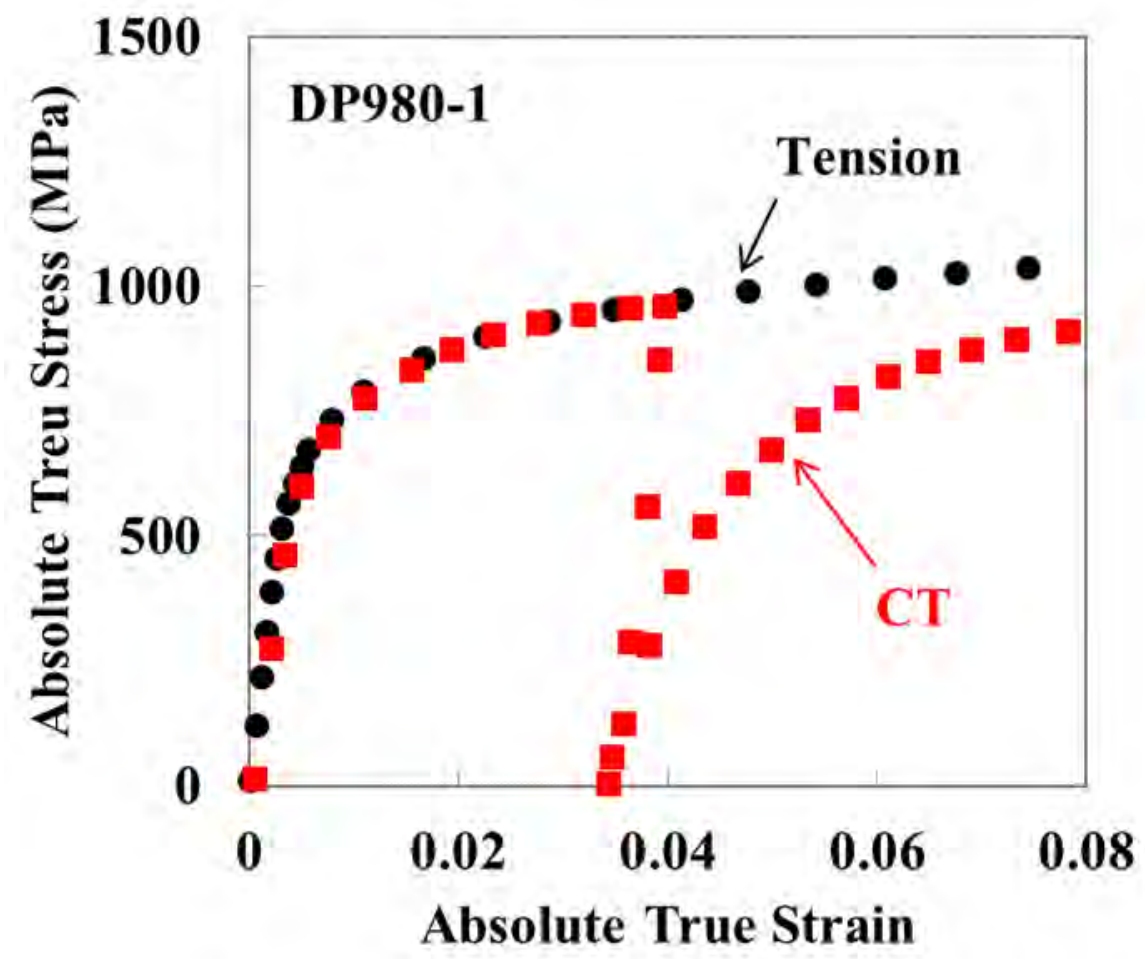

(a) 


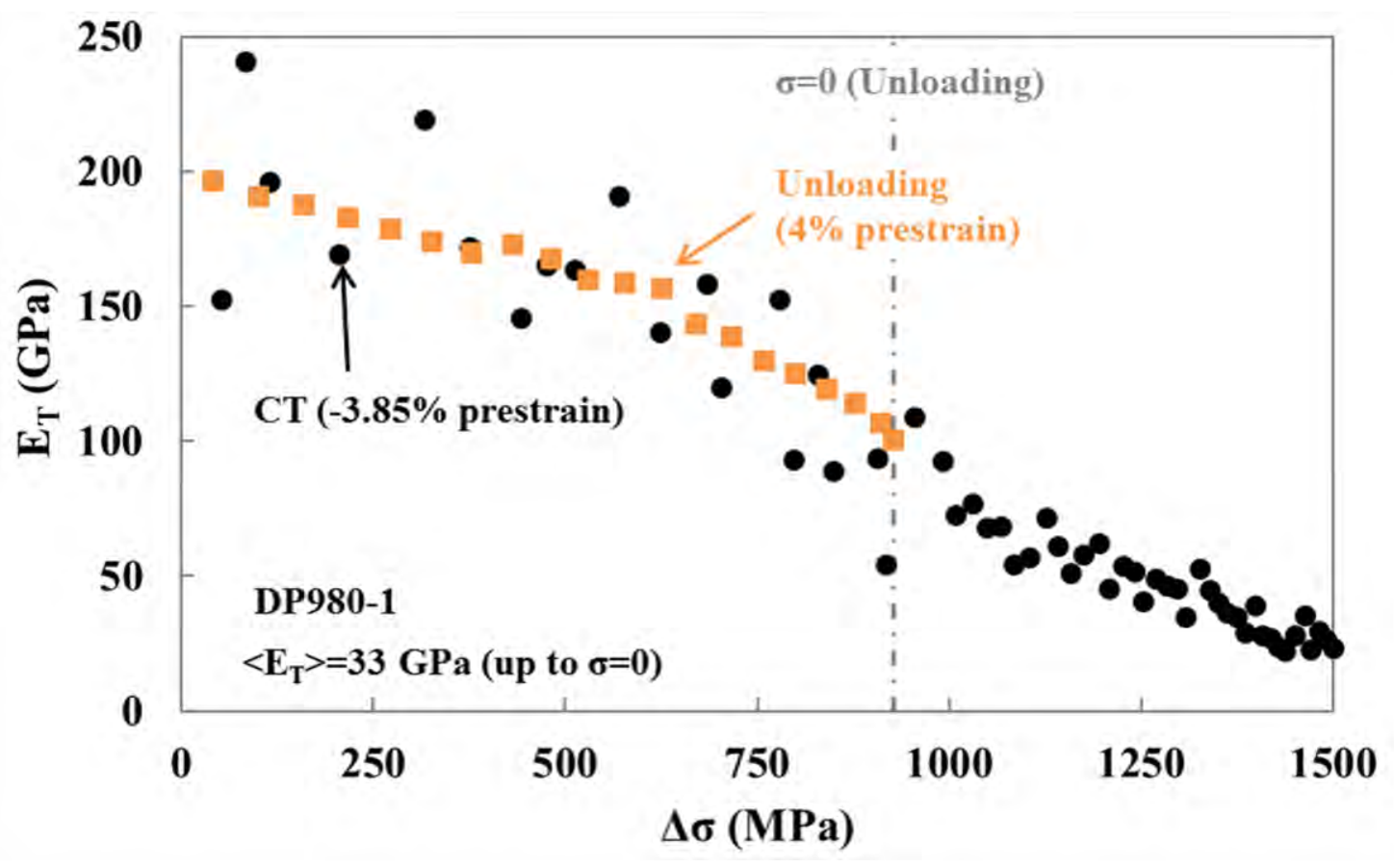

(b)

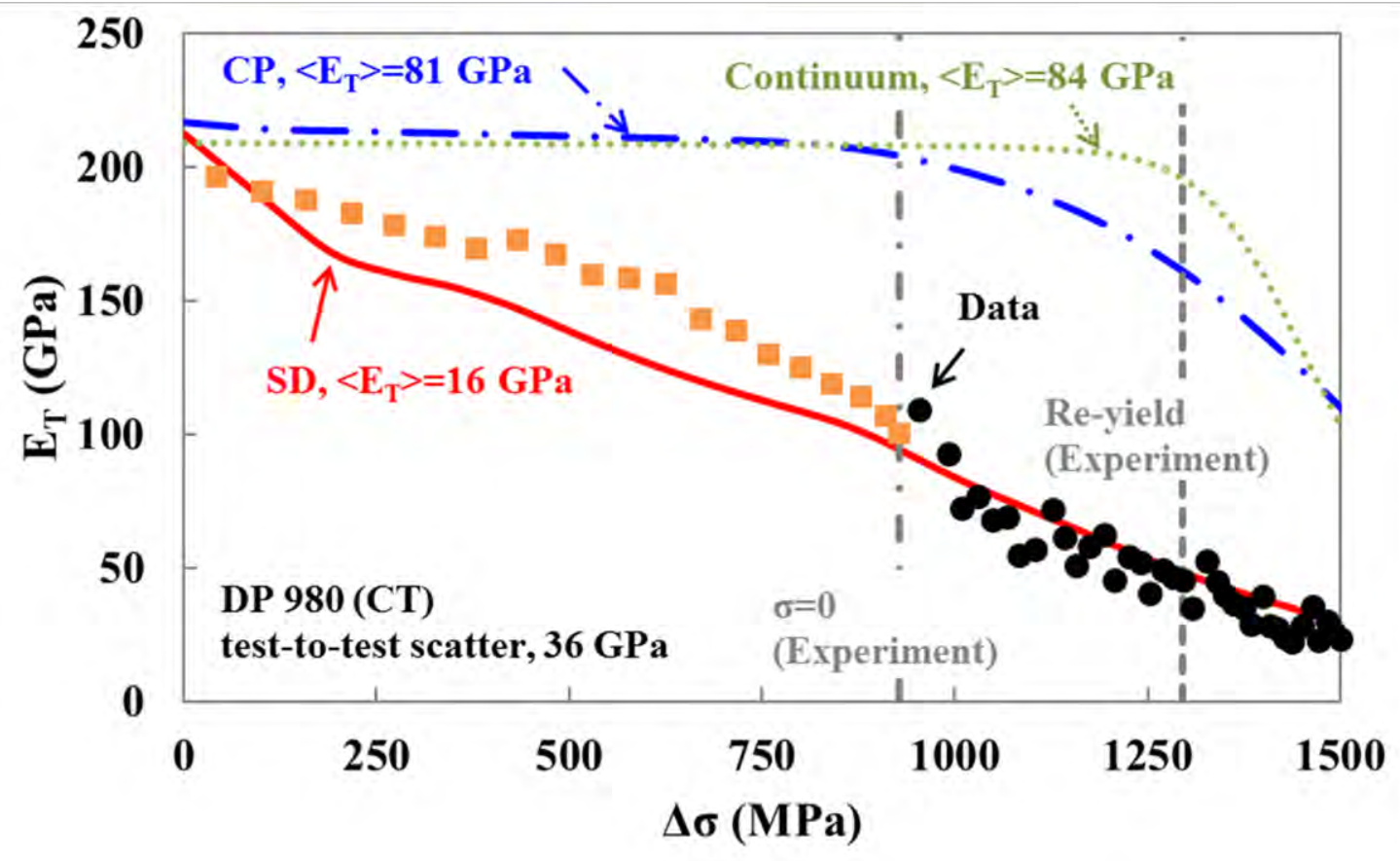

(c)

Fig. 6 (a) CT test result, and CT and LUL tests: (b) comparison of coincident data range, (c) comparison of combined data with predicts of 3 constitutive models.

\section{Discussions}


The abovementioned results demonstrate the dominant importance of including dislocationdislocation interactions in any micro properties to macro behavior linkage for metallic materials. The results are conclusive because the predicted behavior matches independent experiments with remarkable fidelity. A sensitivity study for the SD model, too extensive to be presented here, may be fairly summarized by noting that the only parameter that has substantial uncertainty and significance to the simulation is the rule for assigning obstacle stresses to various grain and phase boundaries.

In order to assess whether altering the magnitude of the obstacle stresses would affect the conclusion, predicted behavior using 3 values of $\tau^{*}$ (Eq. (10)) was compared: $\tau^{*}=1,3$, and 5 times the macro yield stress ( 5 times is the rule used throughout the current work, based on TEM studies in the 1980's [95]). Change this rule involves re-calculating the various constitutive parameters (using the same procedures as already presented), with the results shown in Table 2.

Table 2 Constitutive parameters for SD model for other $\tau^{*}$ rules

\begin{tabular}{lcccc}
\hline & \multicolumn{2}{c}{$\operatorname{SD}\left(\tau^{*}=“ 3 \times ”\right.$ rule $)$} & \multicolumn{2}{c}{$\operatorname{SD}\left(\tau^{*}=\right.$ “" $1 \times ”$ rule $)$} \\
\cline { 2 - 5 } & Ferrite & Martensite & Ferrite & Martensite \\
\hline$\rho_{0}\left(/ \mathrm{m}^{2}\right)$ & $8.93 \times 10^{13}$ & $1.63 \times 10^{15}$ & $8.93 \times 10^{13}$ & $1.63 \times 10^{15}$ \\
$k_{a}$ & & & 59 & \\
$k_{b}$ & & $4 \mathrm{~b}$ & \\
$\tau^{*}(\mathrm{MPa})$ & 1500 & 3190 & 500 & 1063 \\
$g_{0}(\mathrm{MPa})$ & 101 & 286 & 185 & 510 \\
\hline
\end{tabular}

The SD predictions do not vary significantly depending on the value of $\tau^{*}$, and are presented in Fig. 7. The results show that the best choice among these is $\tau^{*}$ equals to 3 times the macro yield stress. This choice halves the standard deviation of $E_{T}$ from $16 \mathrm{GPa}$ to $8 \mathrm{GPa}$. Note from Fig. 6 (c) that this is an order of magnitude better than standard RVE/FE treatments at about 81-84 GPa. 


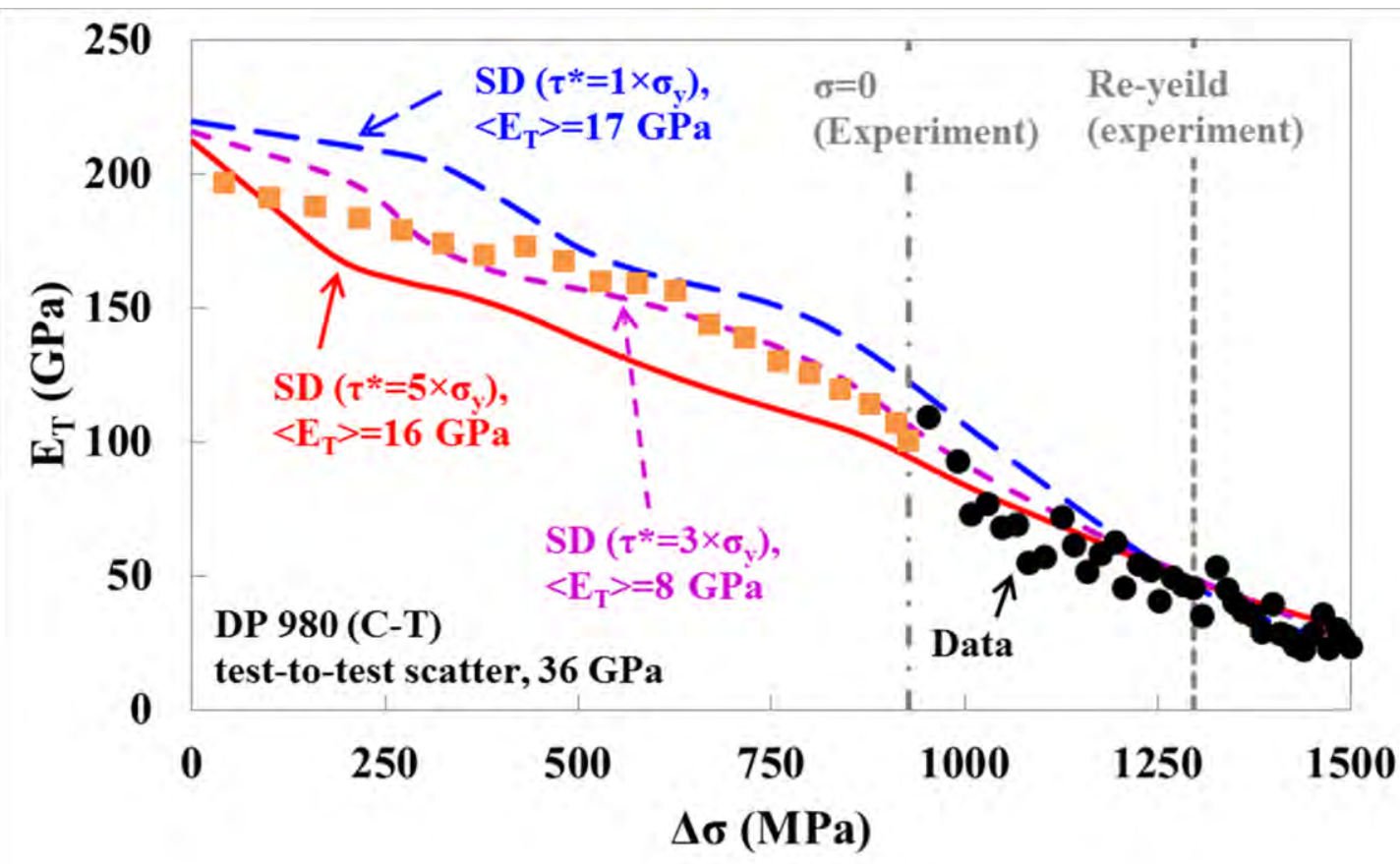

Fig. 7 Comparison of $E_{T}$ vs. $\Delta \sigma$ with various $\tau^{*}$ rules in SD model (CP and

Continuum predictions, unchanged, are already presented in Fig. 6 (b))

\section{Effect of stress inhomogeneity}

The foregoing conclusions differ markedly from a report in the literature [44] that modulus degradation in DP600 steel is a result of stress/strain inhomogeneity, i.e., a continuum effect unrelated to discrete dislocation interactions. Those results were based on a new-RVE (topdown) approach where micro properties are inferred from macro tests (tension) and a hypothesized constitutive model. Our original-RVE approach found little agreement for a continuum model using measured micro properties. The likely source of this discrepancy for the continuum model is the different strength of the martensite phase. The top-down value adopted in [44] is $2600 \mathrm{MPa}$, while our value is $\sim 1650 \mathrm{MPa}$ based on measured martensite strength for the chemical composition of the phase.

In order to clarify whether using unrealistic micro properties can produce spurious conclusions, additional continuum simulations were conducted with modified stress-strain behavior of the individual phases. The martensite strength was increased and the ferrite 
strength was lowered by adjusting $K^{i}$ 's in Eq. (5), while maintaining the same overall stressstrain behavior as in Fig. 4 (a). Two sets of stress-strain curves of the two phases are shown in Fig. 8 (a). Property A represents the original-RVE (bottom-up) approach used for other simulations while Property B represents new-RVE (top-down) fits. Property B is similar to the micro properties used in [44], i.e., UTS of martensite about $2600 \mathrm{MPa}$ and yield stress of ferrite about $400 \mathrm{MPa}^{11}$.

Fig. 8 (b) compares the simulation results for LUL testing with the two sets of properties. While the trend of the Property B simulations is similar to those reported in [44], the same simulations using measured micro properties show virtually no modulus degradation. This illustrates the benefits of the original-RVE approach and the pitfalls of adopting mechanistic conclusions on the basis of being able to reproduce macro behavior without verifying whether the microstructural implications are realistic. 11 The martensite volume fraction assumed in the RVE in [44] is 18\%, but $32 \%$ in this study. This results in the
difference of the overall strength of DP steels, i.e., DP600 [44] vs. DP980 (current study) 


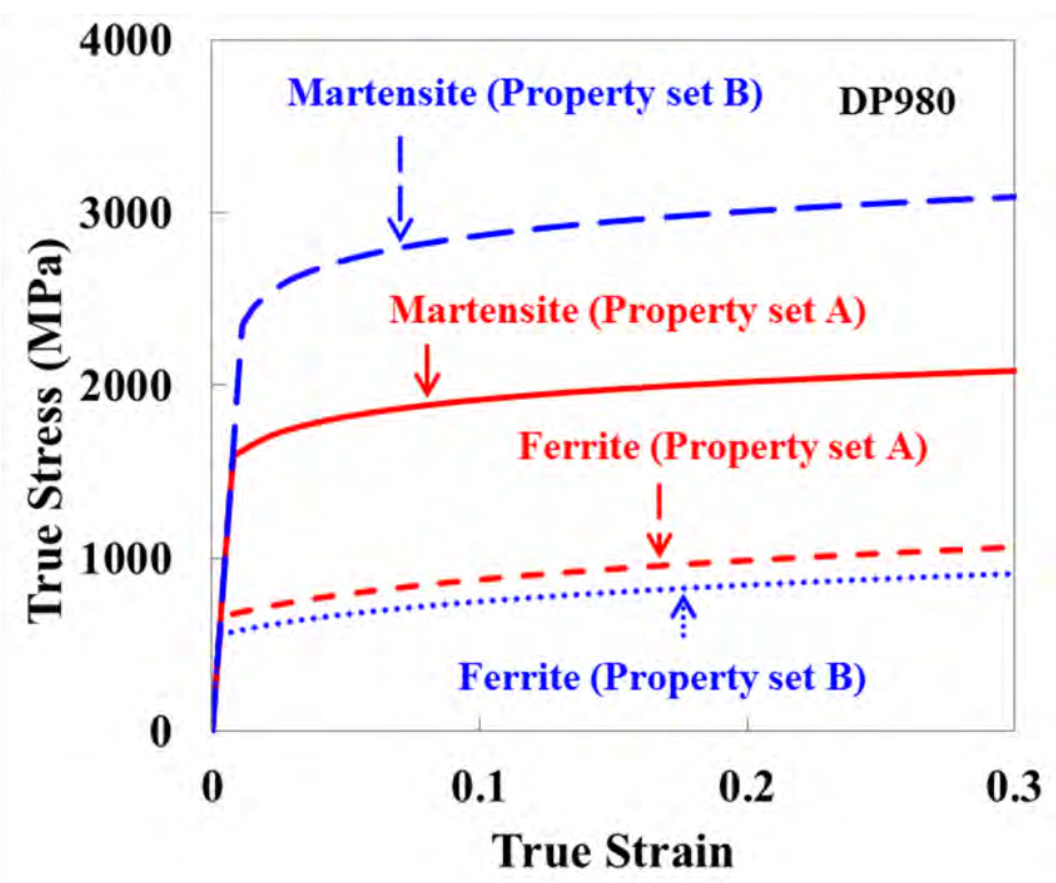

(a)

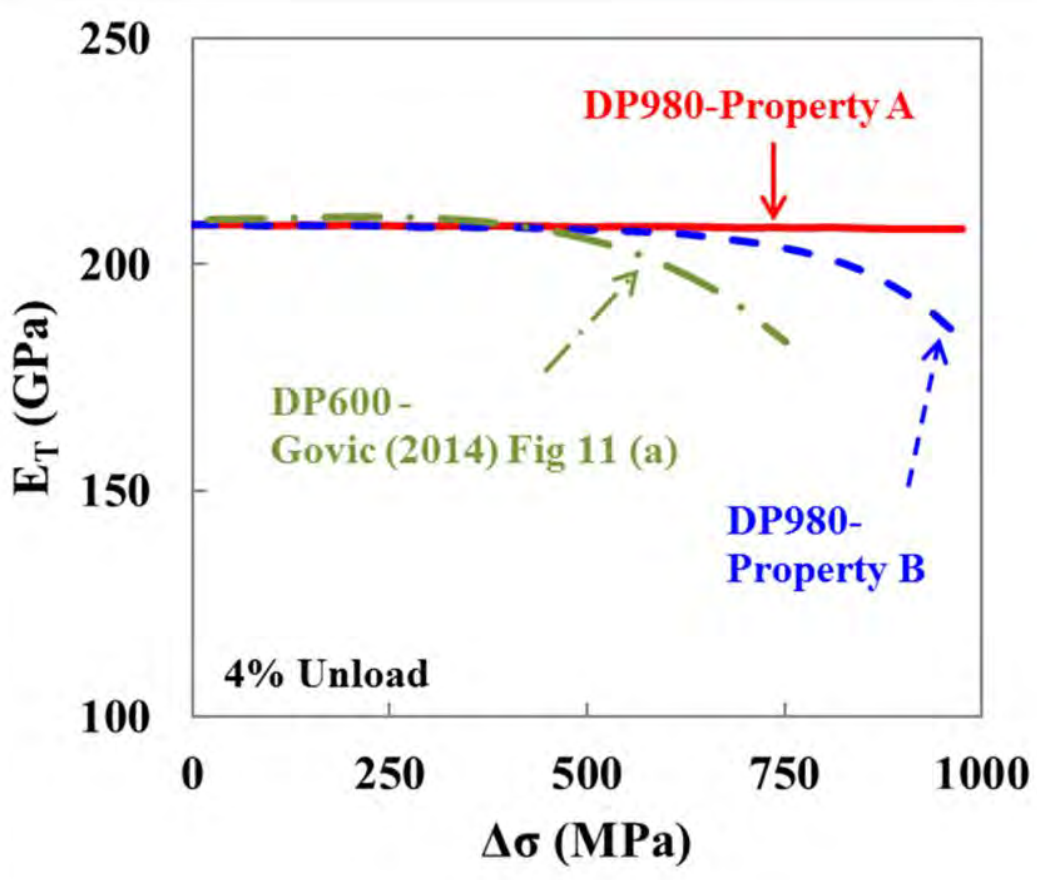

(b)

Fig. 8 Continuum RVE/FE simulations with two sets of constituent phase properties: Property set A represents bottom-up measured values appearing in Table. 1 and Property set B 
represents top-down fit values similar to those appearing in [44]: (a) the constituent stressstrain curves, and (b) simulations of LUL test.

\section{Conclusions}

Bottom-up RVE simulations based on measured micro properties of 3 types were conducted: 1) standard continuum model, 2) CP-FEM model, and 3) SD model (CP-FEM plus the elastic interactions of discrete dislocations). The predicted mechanical behavior of DP980 was compared with independent high-precision experiments of LUL and CT types. The following conclusions were reached:

1) The SD model predicts the strain hardening curve accurately for DP980 steel from micro properties alone while $\mathrm{CP}$ and continuum do not.

2) Non-linear unloading and reloading were predicted of the right form by SD. CP and continuum simulations showed discrepancies with the experiments several times larger than the SD model and with the wrong form.

3) CT test and simulation results are similar to nonlinear loading/unloading except the improvement by including discrete dislocation interaction effects in SD, which reduces standard deviation by a factor of 5 .

4) Nonlinear transition below yield and the Bauschinger effect are manifestations of the elastic interactions of large populations of discrete dislocations.

5) The "original-RVE" approach, based on measured micro properties offers an invaluable tool for revealing mechanistic linkages between micro and macro scales that is not offered by typical top-down "new-RVE" approaches.

\section{Acknowledgments}

This research was supported by U.S. Department of Energy (DOE), Office of Science, Basic Energy Sciences (BES), under Award number DE-SC0012587 and DE-SC-0012483. Authors acknowledge Prof. David Matlock at CSM, Dr. Chen and Prof. Li for greatly helpful discussions. Ken Kushner and Ross Baldwin are also acknowledged gratefully for assistance with mechanical testing in the department of materials science and engineering at OSU. 


\section{Nomenclatures}

\begin{tabular}{|c|c|}
\hline$\sigma_{\text {Composite }}$ & Flow stress of a fiber composite \\
\hline$\sigma_{f}$ & Flow stress of fiber \\
\hline$\sigma_{m}$ & Flow stress of matrix \\
\hline$V_{f}$ & Volume fraction of fiber in the composite \\
\hline$\sigma_{y}$ & Yield stress with no particle \\
\hline$\alpha^{\prime}$ & Constant on the order of unity in Orowan equation (Eq. (2)) \\
\hline$L$ & Particle spacing \\
\hline$\sigma_{0}$ & Frictional stress \\
\hline$k_{y}$ & Material constant in Hall-Petch equation (Eq. (3)) \\
\hline$M$ & Taylor factor \\
\hline$k$ & Material constant related to dislocation character \\
\hline$\tau_{o b s}$ & Obstacle strength \\
\hline$\mu$ & Shear modulus \\
\hline$b$ & Burgers vector \\
\hline$d$ & Grain size \\
\hline E & Young's modulus \\
\hline$v$ & Poisson's ratio \\
\hline$K$ & Strength material constant \\
\hline$\overline{\varepsilon_{0}}$ & Constant that may represent a pre-strain, \\
\hline$n$ & Strain hardening exponent \\
\hline$\tau^{(\alpha)}$ & Resolved shear stress on the $\alpha^{\text {th }}$ slip system \\
\hline$\dot{\gamma}_{0}$ & Reference shear rate \\
\hline$m$ & Strain rate sensitivity \\
\hline$g^{(\alpha)}$ & Slip resistance on the slip system $\alpha$ \\
\hline$g_{0}^{\alpha}$ & Initial slip resistance on the slip system $\alpha$ \\
\hline
\end{tabular}




\begin{tabular}{|c|c|}
\hline$\tau_{b}$ & Back-stress \\
\hline$\rho^{(\alpha)}$ & Dislocation density in slip system $\alpha$ \\
\hline $\boldsymbol{h}_{\alpha \beta}$ & Interaction cosine \\
\hline $\boldsymbol{n}^{(\alpha)}$ & Slip plane normal of slip system $\alpha$ \\
\hline $\boldsymbol{\xi}^{(\beta)}$ & Dislocation line vector of slip system $\beta$ \\
\hline$A$ & Material constant in slip resistance equation (Eq. (7)) \\
\hline$k_{a}$ & Material constant related to dislocation generation \\
\hline$k_{b}$ & Material constant related to dislocation annihilation \\
\hline$\dot{\rho}_{\text {pass }}^{(\alpha)}$ & Rate of dislocation density passing through the element \\
\hline$l^{(\alpha)}$ & Length of the element parallel to the slip plane $\alpha$ \\
\hline$\tau^{*}$ & Maximum obstacle strength \\
\hline$N$ & Geometrical transmissivity factor \\
\hline$L_{1}, L_{i}$ & Intersection line vectors between grain boundary and slip planes \\
\hline$s_{1}, s_{i}$ & $\begin{array}{l}\text { Slip direction vectors of incoming and transmitted dislocations of incoming } \\
\text { and transmitted dislocations }\end{array}$ \\
\hline$E_{T}$ & Instant tangential modulus \\
\hline$\Delta \varepsilon$ & Absolute value of strain change after load reversal \\
\hline$\Delta \sigma$ & Absolute value of stress change after load reversal \\
\hline
\end{tabular}




\section{References}

[1] R. Hill, Elastic properties of reinforced solids: some theoretical principles, J. Mech. Phys. Solids.

http://www.sciencedirect.com/science/article/pii/002250966390036X (accessed March 29, 2016).

[2] A.L. Gurson, Continuum Theory of Ductile Rupture by Void Nucleation and Growth: Part I-Yield Criteria and Flow Rules for Porous Ductile Media, J. Eng. Mater. Technol. 99 (1977) 2-15. http://dx.doi.org/10.1115/1.3443401.

[3] J. Lin, Y. Liu, T. Dean, A Review on Damage Mechanisms, Models and Calibration Methods under Various Deformation Conditions, Int. J. Damage Mech. 14 (2005) 299_319.

[4] W. Zhang, Y. Cai, Review of Damage Mechanics, in: Contin. Damage Mech. Numer. Appl., Springer Berlin Heidelberg, Berlin, Heidelberg, 2010: pp. 15-57. doi:10.1007/978-3-642-04708-4_2.

[5] H. Kim, A.R. Bandar, Y.-P. Yang, J.H. Sung, R.H. Wagoner, Failure Analysis of Advanced High Strength Steels (AHSS) during Draw Bending, in: Proc. IDDRG Mat. Prop. Data More Eff. Num. Anal., Eds. B. S. Levy, D. K. Matlock, C. J. Van Tyne, Colo. Sch. Mines, 2009: pp. 449-460.

[6] A. Needleman, V. Tvergaard, An analysis of ductile rupture in notched bars, J. Mech. Phys. Solids. 32 (1984) 461-490. doi:http://dx.doi.org/10.1016/0022-5096(84)90031-0.

[7] V. Tvergaard, A. Needleman, Analysis of the cup-cone fracture in a round tensile bar, Acta Metall. 32 (1984) 157-169. doi:http://dx.doi.org/10.1016/0001-6160(84)90213-X.

[8] D. Krajcinovic, Damage mechanics, Elsevier, 1996.

[9] G. Voyiadjis, P. Kattan, Advances in damage mechanics : metals and metal matrix composites with an introduction to fabric tensors, Elsevier, 2006.

[10] S. Murakami, Continuum Damage Mechanics, Springer Netherlands, Dordrecht, 2012. doi:10.1007/978-94-007-2666-6.

[11] N. Triantafyllidis, B.N. Maker, On the Comparison Between Microscopic and Macroscopic Instability Mechanisms in a Class of Fiber-Reinforced Composites, J. Appl. Mech. 52 (1985) 794. doi:10.1115/1.3169148.

[12] C.T. Sun, R.S. Vaidya, Prediction of composite properties from a representative 
volume element, Compos. Sci. Technol. 56 (1996) 171-179. doi:10.1016/02663538(95)00141-7.

[13] G.P. Tandon, Use of Composite Cylinder Model as Representative Volume Element for Unidirectional Fiber Composites, J. Compos. Mater. 29 (1995) 388-409. doi:10.1177/002199839502900306.

[14] J. Segurado, J. Llorca, A numerical approximation to the elastic properties of spherereinforced composites, J. Mech. Phys. Solids. 50 (2002) 2107-2121. doi:10.1016/S0022-5096(02)00021-2.

[15] C. GONZALEZ, Numerical simulation of elasto-plastic deformation of composites: evolution of stress microfields and implications for homogenization models, J. Mech. Phys. Solids. 52 (2004) 1573-1593. doi:10.1016/j.jmps.2004.01.002.

[16] W. Wu, G. Jiang, R. Wagoner, G. Daehn, Experimental and numerical investigation of idealized consolidation: part 1: static compaction, Acta Mater. (2000). http://www.sciencedirect.com/science/article/pii/S1359645400002068 (accessed March 29, 2016).

[17] G. Jiang, W. Wu, G. Daehn, R. Wagoner, Experimental and numerical investigation of idealized consolidation: Part II: Cyclic compaction, Acta Mater. (2000). http://www.sciencedirect.com/science/article/pii/S135964540000207X (accessed March 29, 2016).

[18] H. Zhang, G.S. Daehn, R.H. Wagoner, Simulation of the plastic response of whisker reinforced metal matrix composites under thermal cycling conditions, Scr. Metall. Mater. 25 (1991) 2285-2290. doi:10.1016/0956-716X(91)90016-T.

[19] N. Fleck, G. Muller, Strain gradient plasticity: theory and experiment, Acta Metall. ... (1994). http://www.sciencedirect.com/science/article/pii/0956715194905029 (accessed March 30, 2016).

[20] M.E. Gurtin, On a framework for small-deformation viscoplasticity: free energy, microforces, strain gradients, Int. J. Plast. 19 (2003) 47-90. doi:10.1016/S07496419(01)00018-3.

[21] P. Gudmundson, A unified treatment of strain gradient plasticity, J. Mech. Phys. Solids. (2004). http://www.sciencedirect.com/science/article/pii/S0022509603001959 (accessed March 30, 2016). 
[22] W. Nix, H. Gao, Indentation size effects in crystalline materials: a law for strain gradient plasticity, J. Mech. Phys. Solids.

(1998). http://www.sciencedirect.com/science/article/pii/S0022509697000860 (accessed March 30, 2016).

[23] D. Raabe, P. Klose, B. Engl, K.-P. Imlau, F. Friedel, F. Roters, Concepts for Integrating Plastic Anisotropy into Metal Forming Simulations, Adv. Eng. Mater. 4 (2002) 169180. doi:10.1002/1527-2648(200204)4:4<169::AID-ADEM169>3.0.CO;2-G.

[24] J. Stölken, A. Evans, A microbend test method for measuring the plasticity length scale, Acta Mater.

(1998).

http://www.sciencedirect.com/science/article/pii/S1359645498001530 (accessed March 30, 2016).

[25] A. Arsenlis, On the evolution of crystallographic dislocation density in nonhomogeneously deforming crystals, J. Mech. Phys. Solids. 52 (2004) 1213-1246. doi:10.1016/j.jmps.2003.12.007.

[26] A. Ramazani, K. Mukherjee, U. Prahl, W. Bleck, Modelling the effect of microstructural banding on the flow curve behaviour of dual-phase (DP) steels, Comput. Mater. Sci. 52 (2012) 46-54. doi:10.1016/j.commatsci.2011.05.041.

[27] A. Ramazani, K. Mukherjee, A. Schwedt, P. Goravanchi, U. Prahl, W. Bleck, Quantification of the effect of transformation-induced geometrically necessary dislocations on the flow-curve modelling of dual-phase steels, Int. J. Plast. 43 (2013) 128-152. doi:10.1016/j.ijplas.2012.11.003.

[28] S.Y.P. Allain, O. Bouaziz, I. Pushkareva, C.P. Scott, Towards the microstructure design of DP steels: A generic size-sensitive mean-field mechanical model, Mater. Sci. Eng. A. 637 (2015) 222-234. doi:10.1016/j.msea.2015.04.017.

[29] R. Davies, The deformation behavior of a vanadium-strengthened dual phase steel, Metall. Trans. A. (1978). http://link.springer.com/article/10.1007/BF02647169 (accessed March 30, 2016).

[30] G. Garmong, R.B. Thompson, A Theory for the mechanical properties of metal-matrix composites at ultimate loading, Metall. Trans. 4 (1973) 863-873. doi:10.1007/BF02643098.

[31] S.T. Mileiko, The tensile strength and ductility of continuous fibre composites, J. 
Mater. Sci. 4 (1969) 974-977. doi:10.1007/BF00555312.

[32] D.K. Matlock, J.G. Speer, Design Considerations for the Next Generation of Advanced High Strength Sheet Steels, in: Proc. 3rd Int. Conf. Adv. Struct. Steels, 2006: pp. 774781.

[33] D.K. Matlock, J.G. Speer, Third Generation of AHSS: Microstructure Design Concepts, in: Microstruct. Texture Steels, Springer London, London, 2009: pp. 185-205. doi:10.1007/978-1-84882-454-6_11.

[34] E. Orowan, Discussion on Internal Stresses. In Symp. Internal Stresses in Metals and Alloys, London: The Institute of Metals, (1948) 451-453.

[35] E. Orowan, Causes and effects of internal stresses., in: Intern. Stress. Fatigue Met., Detroit, 1958.

[36] E.O. Hall, The Deformation and Ageing of Mild Steel: II Characteristics of the L ders Deformation, Proc. Phys. Soc. Sect. B. 64 (1951) 742-747. doi:10.1088/0370$1301 / 64 / 9 / 302$.

[37] N.J. Petch, The cleavage strength of polycrystals, J. Iron Steel Inst. (1953) 25-28.

[38] W.M. Baldwin, Yield strength of metals as a function of grain size, Acta Metall. 6 (1958) 139-141. doi:10.1016/0001-6160(58)90136-6.

[39] U.F. Kocks, Comments on "Yield strength of metals as a function of grain size," Acta Metall. 7 (1959) 131.

[40] J. Eshelby, F. Frank, F. Nabarro, The equilibrium of linear arrays of dislocations, Philos. Mag. 42 (1951) 351-364.

[41] G. Leibfried, Verteilung von Versetzungen im statischen Gleichgewicht, Zeitschrift Für Phys. 130 (1951) 214-226. doi:10.1007/BF01337695.

[42] J.P. Hirth, J. Lothe, Theory of Dislocations, Krieger Publishing Company, 1969. https://books.google.com/books/about/Theory_of_Dislocations.html?id=LFZGAAAA YAAJ\&pgis=1 (accessed January 14, 2016).

[43] J. Ha, J. Lee, J.H. Kim, F. Barlat, M.-G. Lee, Meso-Scopic Analysis of Strain Path Change Effect on the Hardening Behavior of Dual-Phase Steel, Steel Res. Int. 85 (2014) 1047-1057. doi:10.1002/srin.201300186.

[44] A. Govik, R. Rentmeester, L. Nilsson, A study of the unloading behaviour of dual phase steel, Mater. Sci. Eng. A. 602 (2014) 119-126. doi:10.1016/j.msea.2014.02.069. 
[45] S.K. Paul, Real microstructure based micromechanical model to simulate microstructural level deformation behavior and failure initiation in DP 590 steel, Mater. Des. 44 (2013) 397-406. doi:10.1016/j.matdes.2012.08.023.

[46] S. Sodjit, V. Uthaisangsuk, Microstructure based prediction of strain hardening behavior of dual phase steels, Mater. Des. 41 (2012) 370-379. doi:http://dx.doi.org/10.1016/j.matdes.2012.05.010.

[47] N. Vajragupta, V. Uthaisangsuk, B. Schmaling, S. Münstermann, A. Hartmaier, W. Bleck, A micromechanical damage simulation of dual phase steels using XFEM, Comput. Mater. Sci. 54 (2012) 271-279. doi:10.1016/j.commatsci.2011.10.035.

[48] B.-W. Choi, D.-H. Seo, J.-Y. Yoo, J.-I. Jang, Predicting macroscopic plastic flow of high-performance, dual-phase steel through spherical nanoindentation on each microphase, J. Mater. Res. 24 (2009) 816-822. doi:10.1557/jmr.2009.0109.

[49] X. Sun, K.S. Choi, W.N. Liu, M.A. Khaleel, Predicting failure modes and ductility of dual phase steels using plastic strain localization, Int. J. Plast. 25 (2009) 1888-1909. doi:10.1016/j.ijplas.2008.12.012.

[50] P. Chen, H. Ghassemi-Armaki, S. Kumar, A. Bower, S. Bhat, S. Sadagopan, Microscale-calibrated modeling of the deformation response of dual-phase steels, Acta Mater. 65 (2014) 133-149. doi:10.1016/j.actamat.2013.11.036.

[51] H. Ghassemi-Armaki, R. Maaß, S.P. Bhat, S. Sriram, J.R. Greer, K.S. Kumar, Deformation response of ferrite and martensite in a dual-phase steel, Acta Mater. 62 (2014) 197-211. doi:10.1016/j.actamat.2013.10.001.

[52] G. Krauss, Martensite in steel: strength and structure, Mater. Sci. Eng. A. (1999). http://www.sciencedirect.com/science/article/pii/S0921509399002889 (accessed January 14, 2016).

[53] W. Woo, V.T. Em, E.-Y. Kim, S.H. Han, Y.S. Han, S.-H. Choi, Stress-strain relationship between ferrite and martensite in a dual-phase steel studied by in situ neutron diffraction and crystal plasticity theories, Acta Mater. 60 (2012) 6972-6981. doi:10.1016/j.actamat.2012.08.054.

[54] M.A. Melchior, J.-F. Remacle, L. Delannay, Crystal-Plasticity-Based FE Modelling Of A Dual-Phase Microstructure In Which Grains Have Non-Uniform Shape And Size, in: AIP Conf. Proc., AIP, 2007: pp. 381-386. doi:10.1063/1.2740841. 
[55] S.R. Kalidindi, C.A. Bronkhorst, L. Anand, Crystallographic texture evolution in bulk deformation processing of FCC metals, J. Mech. Phys. Solids. 40 (1992) 537-569. doi:10.1016/0022-5096(92)80003-9.

[56] P.R. Dawson, Computational crystal plasticity, Int. J. Solids Struct. 37 (2000) 115-130. doi:10.1016/S0020-7683(99)00083-9.

[57] A. Ma, F. Roters, D. Raabe, A dislocation density based constitutive model for crystal plasticity FEM including geometrically necessary dislocations, Acta Mater. 54 (2006) 2169-2179. doi:10.1016/j.actamat.2006.01.005.

[58] D. Raabe, D. Ma, F. Roters, Effects of initial orientation, sample geometry and friction on anisotropy and crystallographic orientation changes in single crystal microcompression deformation: A crystal plasticity finite element study, Acta Mater. 55 (2007) 4567-4583. doi:10.1016/j.actamat.2007.04.023.

[59] D. Raabe, P. Klose, B. Engl, Concepts for integrating plastic anisotropy into metal forming simulations, Adv. … (2002). http://www.dierkraabe.com/app/download/5800398691/Advanced+Engin+Materials+Raabe+Klose+ov erview+mechanical+anisotropy+2002.pdf (accessed May 28, 2016).

[60] H. Lim, M.G. Lee, J.H. Kim, B.L. Adams, R.H. Wagoner, Simulation of polycrystal deformation with grain and grain boundary effects, Int. J. Plast. 27 (2011) 1328-1354. doi:10.1016/j.ijplas.2011.03.001.

[61] H. Lim, S. Subedi, D.T. Fullwood, B.L. Adams, R.H. Wagoner, A Practical Meso-Scale Polycrystal Model to Predict Dislocation Densities and the Hall ${ }^{\wedge}{ }^{\wedge}$ ndash;Petch Effect, Mater. Trans. 55 (2014) 35-38. doi:10.2320/matertrans.MA201305.

[62] M.G. Lee, H. Lim, B.L. Adams, J.P. Hirth, R.H. Wagoner, A dislocation density-based single crystal constitutive equation, Int. J. Plast. 26 (2010) 925-938. doi:http://dx.doi.org/10.1016/j.ijplas.2009.11.004.

[63] D. Peirce, R.J. Asaro, A. Needleman, An analysis of nonuniform and localized deformation in ductile single crystals, Acta Metall. 30 (1982) 1087-1119. doi:10.1016/0001-6160(82)90005-0.

[64] R.J. Asaro, Advances in Applied Mechanics Volume 23, Elsevier, 1983. doi:10.1016/S0065-2156(08)70242-4.

[65] S.R. (Surya R. Kalidindi, Polycrystal plasticity: constitutive modeling and 
deformation processing, Massachusetts Institute of Technology, 1992. http://dspace.mit.edu/handle/1721.1/13146 (accessed May 4, 2016).

[66] W. Gan, H.J. Bong, H. Lim, R.K. Boger, F. Barlat, R.H. Wagoner, Mechanism of the Bauschinger Effect in "Hard Pin” Al-Ge-Si Alloys, Mater. Sci. Eng. A. 684 (2016) 353-372.

[67] W. Gan, PRECIPITATION AND STRENGTHENING IN AL-GE-SI ALLOYS, The Ohio State University, 2005.

[68] J. Lee, J.Y. Lee, F. Barlat, R.H. Wagoner, K. Chung, M.-G. Lee, Extension of quasiplastic-elastic approach to incorporate complex plastic flow behavior - application to springback of advanced high-strength steels, Int. J. Plast. 45 (2013) 140-159. doi:http://dx.doi.org/10.1016/j.ijplas.2013.01.011.

[69] R.. Cleveland, A.. Ghosh, Inelastic effects on springback in metals, Int. J. Plast. 18 (2002) 769-785. doi:10.1016/S0749-6419(01)00054-7.

[70] J.-W. Lee, M.-G. Lee, F. Barlat, Finite element modeling using homogeneous anisotropic hardening and application to spring-back prediction, Int. J. Plast. 29 (2012) 13-41. doi:10.1016/j.ijplas.2011.07.007.

[71] M.-G. Lee, D. Kim, C. Kim, M.L. Wenner, K. Chung, Spring-back evaluation of automotive sheets based on isotropic-kinematic hardening laws and non-quadratic anisotropic yield functions, part III: applications, Int. J. Plast. 21 (2005) 915-953. doi:10.1016/j.ijplas.2004.05.014.

[72] S. Zang, M.-G. Lee, L. Sun, J.H. Kim, Measurement of the Bauschinger behavior of sheet metals by three-point bending springback test with pre-strained strips, Int. J. Plast. 59 (2014) 84-107. doi:http://dx.doi.org/10.1016/j.ijplas.2014.03.015.

[73] F. Yoshida, T. Uemori, A model of large-strain cyclic plasticity and its application to springback simulation, Int. J. Mech. Sci. 45 (2003) 1687-1702. doi:10.1016/j.ijmecsci.2003.10.013.

[74] L. Sun, R.H. Wagoner, Complex unloading behavior: Nature of the deformation and its consistent constitutive representation, Int. J. Plast. 27 (2011) 1126-1144. doi:10.1016/j.ijplas.2010.12.003.

[75] M.G. Lee, J.W. Lee, J.J. Gracio, G. Vincze, E.F. Rauch, F. Barlat, A dislocation-based hardening model incorporated into an anisotropic hardening approach, Comput. Mater. 
Sci. 79 (2013) 570-583. doi:10.1016/j.commatsci.2013.05.056.

[76] Z. Chen, U. Gandhi, J. Lee, R.H. Wagoner, Variation and consistency of Young's modulus in steel, J. Mater. Process. Technol. 227 (2016) 227-243. doi:10.1016/j.jmatprotec.2015.08.024.

[77] Z. Chen, H.J. Bong, D. Li, R.H. Wagoner, The elastic-plastic transition of metals, Int. J. Plast. 83 (2016) 178-201. doi:10.1016/j.ijplas.2016.04.009.

[78] R.K. Boger, R.H. Wagoner, F. Barlat, M.G. Lee, K. Chung, Continuous, large strain, tension/compression testing of sheet material, Int. J. Plast. 21 (2005) 2319-2343. doi:10.1016/j.ijplas.2004.12.002.

[79] K. Piao, J.K.K. Lee, J.H.H. Kim, H.Y.Y. Kim, K. Chung, F. Barlat, R.H. Wagoner, A sheet tension/compression test for elevated temperature, Int. J. Plast. 38 (2012) 27-46. doi:http://dx.doi.org/10.1016/j.ijplas.2012.03.009.

[80] K. Piao, K. Chung, M.-G. Lee, R.H. Wagoner, Twinning-Slip Transitions in Mg AZ31B, Metall. Mater. Trans. A. 43 (2012) 3300-3313. doi:10.1007/s11661-012-11540 .

[81] J.A. Benito, J. Jorba, J.M. Manero, A. Roca, Change of Young's modulus of colddeformed pure iron in a tensile test, Metall. Mater. Trans. A. 36 (2005) 3317-3324. doi:10.1007/s11661-005-0006-6.

[82] L. Luo, A.K. Ghosh, Elastic and Inelastic Recovery After Plastic Deformation of DQSK Steel Sheet, J. Eng. Mater. Technol. 125 (2003) 237. doi:10.1115/1.1491574.

[83] P. van Liempt, J. Sietsma, A physically based yield criterion I. Determination of the yield stress based on analysis of pre-yield dislocation behaviour, Mater. Sci. Eng. A. 662 (2016) 80-87. doi:http://dx.doi.org/10.1016/j.msea.2016.03.013.

[84] D.L. McDowell, Viscoplasticity of heterogeneous metallic materials, Mater. Sci. Eng. R Reports. 62 (2008) 67-123. doi:http://dx.doi.org/10.1016/j.mser.2008.04.003.

[85] S. Tiwari, G.J. Tucker, D.L. McDowell, Simulated defect growth avalanches during deformation of nanocrystalline copper, Philos. Mag. 93 (2013) 478-498. doi:10.1080/14786435.2012.722236.

[86] M. Kato, T. Fujii, S. Onaka, Dislocation Bow-Out Model for Yield Stress of Ultra-Fine Grained Materials, Mater. Trans. $49 \quad$ (2008) 1278-1283. doi:10.2320/matertrans.MRA2008012. 
[87] J.H. Kim, D. Kim, F. Barlat, M.-G. Lee, Crystal plasticity approach for predicting the Bauschinger effect in dual-phase steels, Mater. Sci. Eng. A. 539 (2012) 259-270. doi:10.1016/j.msea.2012.01.092.

[88] J.R. Rice, Inelastic constitutive relations for solids: An internal-variable theory and its application to metal plasticity, J. Mech. Phys. Solids. 19 (1971) 433-455. doi:10.1016/0022-5096(71)90010-X.

[89] J. Gubicza, N.Q. Chinh, J.L. Lábár, S. Dobatkin, Z. Hegedüs, T.G. Langdon, Correlation between microstructure and mechanical properties of severely deformed metals, J. Alloys Compd. 483 (2009) 271-274. doi:10.1016/j.jallcom.2008.07.200.

[90] H. Wiedersich, Hardening mechanisms and the theory of deformation, JOM. (1964). https://scholar.google.com/scholar? cluster=3706413268813347386\&hl=ko\&oi=schola rr\#0 (accessed January 13, 2016).

[91] G. Schoeck, R. Frydman, The contribution of the dislocation forest to the flow stress, Phys. Status Solidi. http://onlinelibrary.wiley.com/doi/10.1002/pssb.2220530227/abstract (accessed January 13, 2016).

[92] M. Kassner, A case for Taylor hardening during primary and steady-state creep in aluminium and type 304 stainless steel, J. Mater. Sci. (1990). http://link.springer.com/article/10.1007/BF01045755 (accessed January 13, 2016).

[93] U.F. Kocks, LAWS FOR WORK-HARDENING AND LOW-TEMPERATURE CREEP., J. Eng. Mater. Technol. Trans. ASME. 98 Ser H (1976) 76-85. doi:10.1115/1.3443340.

[94] E. Orowan, Problems of plastic gliding, Proc. Phys. Soc. 52 (1940) 8-22. doi:10.1088/0959-5309/52/1/303.

[95] Z. Shen, R.H. Wagoner, W.A.T. Clark, Dislocation pile-up and grain boundary interactions in 304 stainless steel, Scr. Metall. 20 (1986) 921-926. doi:10.1016/00369748(86)90467-9.

[96] G. Simmons, H.F. Wang, Single Crystal Elastic Constants and Calculated Aggregate Properties: A Hand Book, (1971). https://www.researchgate.net/publication/243777190_Single_Crystal_Elastic_Constant s_and_Calculated_Aggregate_Properties_A_Hand_Book (accessed January 14, 2016). 
[97] A.S. Keh, Work hardening and deformation sub-structure in iron single crystals deformed in tension at $298^{\circ} \mathrm{k}$, Philos. Mag. 12 (1965) 9-30. doi:10.1080/14786436508224942.

[98] M. Charleux, W.J. Poole, M. Militzer, A. Deschamps, Precipitation behavior and its effect on strengthening of an HSLA-Nb/Ti steel, Metall. Mater. Trans. A. 32 (2001) 1635-1647. doi:10.1007/s11661-001-0142-6.

[99] S. Morito, J. Nishikawa, T. Maki, Dislocation density within lath martensite in Fe-C and Fe-Ni alloys, ISIJ http://jlc.jst.go.jp/JST.Journalarchive/isijinternational1989/43.1475?from=Google (accessed January 14, 2016).

[100] M.D. Taylor, D.K. Matlock, E. De Moor, J.G. Speer, Development of a Plane Strain Tensile Geometry to Assess Shear Fracture in Dual Phase Steels, J. Mater. Eng. Perform. 23 (2014) 3685-3694. doi:10.1007/s11665-014-1154-x.

[101] M.D. Taylor, K.S. Choi, X. Sun, D.K. Matlock, C.E. Packard, L. Xu, F. Barlat, Correlations between nanoindentation hardness and macroscopic mechanical properties in DP980 steels, Mater. Sci. Eng. A. 597 (2014) 431-439. doi:10.1016/j.msea.2013.12.084.

[102] R. Song, D. Ponge, D. Raabe, J.G. Speer, D.K. Matlock, Overview of processing, microstructure and mechanical properties of ultrafine grained bcc steels, Mater. Sci. Eng. A. 441 (2006) 1-17. doi:10.1016/j.msea.2006.08.095.

[103] R.J. Asaro, A. Needleman, Overview no. 42 Texture development and strain hardening in rate dependent polycrystals, Acta Metall. 33 (1985) 923-953. doi:10.1016/00016160(85)90188-9. 